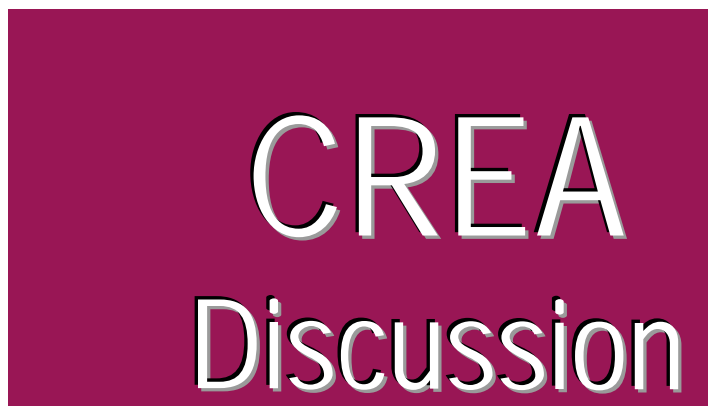
Paper \title{
2013-27
}

Center for Research in Economic Analysis

University of Luxembourg

\section{Capital- and Labor-Saving Technical Change in an Aging Economy}

available online : http://wwwfr.uni.lu/recherche/fdef/crea/publications2/discussion_papers

Andreas Irmen, CREA, Université du Luxembourg

November, 2013

For editorial correspondence, please contact: crea@uni.lu

University of Luxembourg

Faculty of Law, Economics and Finance $162 \mathrm{~A}$, avenue de la Faïencerie

L-1511 Luxembourg 


\title{
CAPITAL- AND LABOR-SAVING TECHNICAL CHANGE IN AN AGING ECONOMY
}

\author{
Andreas Irmen* \\ University of Luxembourg and CESifo, Munich
}

\begin{abstract}
Does population aging and the associated increase in the old-age dependency ratio affect economic growth? The answer is given in a novel analytical framework that allows for population aging to affect endogenous capital- and labor-saving technical change. The short-run analysis reveals that population aging induces more labor- and less capital-saving technical change as it increases the relative scarcity of labor with respect to capital. Due to external contemporaneous knowledge spill-overs across innovating firms induced technical change has a first-order effect on current aggregate income. In the long-run capitalsaving technical progress vanishes, and the economy's growth rate reflects only labor-saving technical change. However, the mere possibility of capital-saving technical change is shown to imply that the economy's steady-state growth rate becomes independent of its age structure: neither a higher life-expectancy nor a decline in fertility affects economic growth in the long run.
\end{abstract}

Keywords: Demographic Transition, Capital Accumulation, Direction of Technical Change.

JEL-Classification: D91, D92, O33, O41.

This Version: November 8, 2013.

\footnotetext{
*University of Luxembourg, Faculty of Law, Economics and Finance, 162a, avenue de la Faïencerie, L-1511 Luxembourg, Luxembourg, airmen@uni.lu.

I am grateful to Volker Böhm, Oded Galor, Hendrik Hakenes, Burkhard Heer, Johanna Kuehnel, Anastasia Litina, Isabel Schnabel, Robert Stelter, Gautam Tripati, Edgar Vogel, Benteng Zou, audiences at Antwerp, Copenhagen, Mannheim, Frankfurt, Hannover, Heidelberg, Lisbon, Luxembourg, Stockholm, Trier, Vielsalm, and Mainz for helpful comments. Finally, I would like to thank Déborah Schwartz and Amer Tabakovic for competent research assistance.
} 


\section{Introduction}

Population aging, defined as the process by which older individuals become a proportionally larger fraction of the total population, has been the predominant demographic phenomenon in many countries over the last decades and is predicted to reach unprecedented heights. Table 1 shows actual data and forecasts of the United Nations concerning the old-age dependency ratio (OADR) for several countries and regions. ${ }^{1}$ Roughly speaking, between 2005 and 2050 the OADR is projected to double in Europe and the United States of America. For China, India, Japan and the entire planet its predicted increase is even more pronounced.

There is widespread consensus that these trends have two main causes, a decline in fertility and an increase in longevity (see, e. g., Weil (2008)). ${ }^{2}$ The present paper starts from this premise and asks whether and how population aging and the associated increase in the OADR affect economic growth. For at least two reasons, this question is at the heart of many policy debates both in the developed and the developing world.

First, there is an increasing awareness in the industrial nations that population aging poses serious challenges for many important fields of economic policy including health care systems, pension schemes, or public debt (see, e. g., World Health Organization (2009) or Börsch-Supan (2012)). In the political arena economic growth is often seen as a means to solve, or at least to alleviate these problems (see, e. g., Merkel (2009)). To gauge this prospect it is fundamental to know whether population aging per se may be the cause of faster or slower economic growth. Second, due to improvements in the quality of the daily nutritional intake, in the level of public health, or in the availability of vaccination and medical treatments longevity has been increasing in large parts of the world since the 19th century (Maddison (2001), Oeppen and Vaupel (2002), Cutler, Deaton, and Lleras-Muney (2006)). Currently, this observation gives rise to an intense debate about whether these improvements also cause faster economic growth and whether development policy should focus on them to foster growth (see, e.g.,

\footnotetext{
${ }^{1}$ The predictions appear in United Nations (2013) as the 'medium fertility variant'. The oldage dependency ratio is the ratio of the population aged 65 or over to the population aged 15-64. This ratio is stated as the number of dependants per 100 persons of working age 15-64. I focus on the OADR as an indicator of population aging since this measure has a natural counterpart in the theoretical analysis that follows.

${ }^{2}$ During a demographic transition a decline in fertility will increase the OADR because fewer young people enter the labor force than there are old workers leaving it. A higher longevity means an increase in the number of years an individual is old. This increases the OADR by raising the number of retired persons alive.
} 
Table 1: Old-Age Dependency Ratios in Selected Countries and Regions (United Nations (2013)).

\begin{tabular}{|c||c|c|c|c|c|c|}
\hline Year & World & Europe & USA & China & India & Japan \\
\hline \hline 2005 & 11 & 23 & 18 & 11 & 8 & 30 \\
\hline 2050 & 25 & 47 & 36 & 39 & 19 & 72 \\
\hline
\end{tabular}

Ashraf, Lester, and Weil (2009)). ${ }^{3}$ However, a comprehensive answer to these questions must account for the potential effect of longevity on economic growth through population aging, a channel so far neglected in the literature.

Existing theories have primarily focussed on the adverse effects of population aging on economic growth (see, e. g., Bös and von Weizsäcker (1989)). In contrast, I argue that these theories neglect an important mechanism that may mitigate or even offset any effect of population aging on economic growth. This mechanism emphasizes that firms adjust their investment behavior in aging economies. Since these investments constitute a crucial determinant of the speed of technical progress, population aging has the potential to affect the growth performance of an economy, both in the short run and in the long run.

I address this issue in a novel growth model that allows for endogenous capitaland labor-saving technical change. This feature turns out to substantially modify the predicted effects of population aging on economic growth. The production side of the economy builds on and extends ideas of the so-called 'induced innovations' literature (see, e. g., Hicks (1932) and Drandakis and Phelps (1966)). According to this literature relative factor prices reflect the relative scarcity of factors and induce innovations that raise the productivity of the relatively scarcer and more expensive factor. In line with this reasoning, my framework highlights that population aging increases the relative scarcity of labor with respect to capital. This tendency increases the real wage relative to the real rental rate of capital

\footnotetext{
${ }^{3}$ The related empirical literature delivers mixed results on the potential causal effects on growth (see, e. g., Acemoglu and Johnson (2007), Lorentzen, McMillan, and Wacziarg (2008), or Cervellati and Sunde (2011)).
} 
and induces more labor-saving and less capital-saving technical change. ${ }^{4} \mathrm{How}$ ever, unlike the 'induced innovations' literature, the investment behavior of competitive firms is fully micro-founded in the present paper. To accomplish this I introduce a production function defined over "types of tasks" performed by either capital or labor.

The household side has two-period lived overlapping generations as in Allais (1947), Samuelson (1958), or Diamond (1965). Individuals face a survival probability when they enter the second period of their lives. This framework allows for a straightforward representation of population aging as an increase in the OADR. Both, a decline in fertility and an increase in the survival probability of the current young, augment this ratio in the next period. These demographic changes are meant to capture the tendency shown in Table 1.

My analysis derives two main sets of results concerning the relationship between population aging and economic growth. The first set concerns the short-run effects of population aging. These results are based on the comparison of two initially identical economies with a differing demographic evolution between two adjacent periods. As a consequence, one of the two economies ends up with a greater OADR in the second period. I refer to this economy as the 'older' one.

My findings do not support the view that population aging necessarily slows down growth in the short run. On the contrary, they highlight that the source of aging matters, both for the kind of growth effects and their sign.

For instance, aggregate income is predicted to grow faster in the older economy if population aging is due to a higher life-expectancy. Anticipating this, households increase their savings. This leads to a larger capital stock and induces faster labor productivity growth. Both channels increase aggregate income. ${ }^{5}$ These forces also drive per-capita income growth. However, their impact is mitigated in the older economy since a higher life-expectancy also increases total population.

\footnotetext{
${ }^{4}$ This chain of reasoning associates the phenomenon of population aging with the famous contention of John Hicks (Hicks (1932), p.124-125) on induced inventions according to which "A change in the relative prices of the factors of production is itself a spur to invention, and to invention of a particular kind - directed to economising the use of a factor which has become relatively expensive. The general tendency to a more rapid increase of capital than labour which has marked European history during the last few centuries has naturally provided a stimulus to labour-saving inventions."

${ }^{5}$ As will be explained in the main text below, the first-order effect of induced technical progress on aggregate income is due to the presence of external contemporaneous knowledge spill-overs across investing firms.
} 
Alternatively, if aging is due to a decline in fertility, then the older economy has a smaller workforce and aggregate income is predicted to fall. However, this effect is mitigated since a shrinking workforce also induces more labor-saving investments, hence, faster labor productivity growth. As the negative size effect of a shrinking workforce dominates the induced effect on labor productivity, aggregate income growth is slower in the older economy. This conclusion is strengthened if households reduce their savings in anticipation of a lower rental rate of capital. Then, the older economy has not only less labor but also less capital at its disposal. Still, the growth rate of per-capita income may be greater in the older economy since a lower fertility rate also decreases total population.

The second set of results is related to the long-run effects of population aging. I establish that the steady-state growth rate of per-worker variables is given by the growth rate of labor-saving technological knowledge alone. Moreover, this growth rate is independent of population aging. The latter property is shown to be due to the mere possibility of endogenous capital-saving technical change.

The intuition behind this finding is linked to the logic of the Generalized SteadyState Growth Theorem devised in Irmen (2013). This theorem generalizes Uzawa's Steady-State Growth Theorem (Uzawa (1961)) to endogenous-growth economies including the one studied in the present paper. Roughly speaking, it states that only labor-saving technical change can occur in the steady state of a neoclassical economy that uses some of its current output to generate technical progress. Thus, asymptotically, capital-saving technical change must vanish. For the steady state of the economy under scrutiny here this requires that the stock of capitalsaving technological knowledge remains constant over time. Hence, the steady state must induce capital-saving technical progress just sufficient to offset the depreciation of this stock. This requirement determines a time-invariant steadystate level of the 'efficient capital intensity', the economy's state variable. The determination of this level reflects two facets of the production sector, namely, the way capital-saving technological knowledge accumulates and the equilibrium incentives to engage in capital-saving technical change. Population aging does not interfere with its determination. As the steady-state level of the efficient capital intensity also determines the growth rate of labor-saving technical progress, the steady-state growth rate of the economy does not hinge on population aging either.

There are at least two ways to link these findings to the recent experience of the US economy. First, as shown in Figure 1.1 for the time span between 1960 and 2012, the evolution of the OADR, of per-capita GDP growth, and of labor 
Figure 1.1: Old-Age Dependency Ratio (OADR) and Annual Growth Rates of Per-capita GDP and GDP per Person Employed: US, 1960-2012.

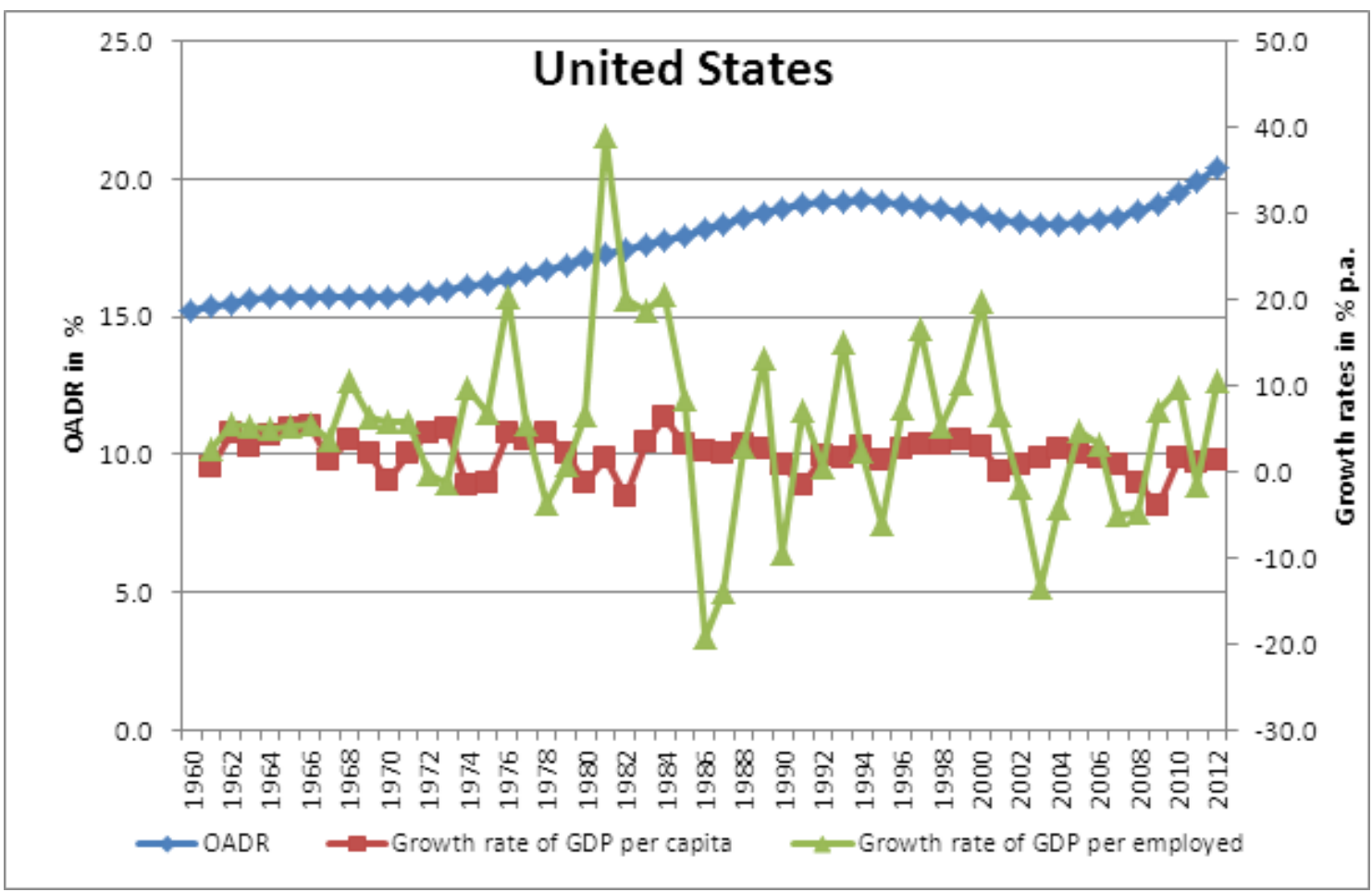

productivity growth appear uncorrelated. ${ }^{6}$ This is consistent with the predicted effect of population aging on steady-state growth in the economy with endogenous capital-saving technical change. Second, as shown by Klump, McAdam, and Willman (2007) for the period 1953 to 1998, the US economy exhibited exponential labor-saving technical change whereas capital-saving technical change faded away. This is consistent with the predicted behavior of technical change in the neighborhood of the steady state of the economy with endogenous capitalsaving technical change.

\footnotetext{
${ }^{6}$ In Figure 1.1 the old-age dependency ratio (OADR) is the ratio of the population aged 65 and older per 100 persons of the working-age population aged 15-64. GDP per capita is gross domestic product divided by midyear population. Data on these variables are from World Bank (2013). Data on GDP per person employed is taken from European Commission - Economic and Financial Affairs - AMECO (2013). The impression of zero correlation is confirmed when percapita GDP or GDP per person employed is regressed on the OADR and a time trend. Then, the impact of the OADR on the outcome is statistically not different from zero. The $p$-value in both regressions is larger than 0.6. The detailed regression results are available from the author upon request.
} 
This paper is organized as follows. Section 2 discusses the link to the existing literature. Section 3 presents the details of the model. Section 4 studies the intertemporal general equilibrium and establishes the dynamical system. Section 5 contains the main results of this paper on the short-run and the long-run implications of population aging for economic growth. Additional results are derived in Section 6. In Section 6.1, I revisit the role of capital-saving technical change and identify this form of technical change as the main reason for why steady-state growth is independent of population aging. The following sections allow for various new features. They highlight the robustness of my results for the long-run and discuss necessary modifications for the short-run analysis. Section 6.2 shows that all qualitative results remain valid if capital-saving investments generate external contemporaneous knowledge spill-overs in the spirit of Frankel (1962) and Romer (1986). Section 6.3 addresses the issues of having three generations alive in each period and of myopic expectations of survival rates. Section 6.4 endogenizes the supply of labor, Section 6.5 sketches the role of endogenous fertility. Section 7 concludes. Proofs are relegated to Section 8, the Appendix.

\section{Related Literature}

This paper builds on and contributes to several strands of the literature. First, it relates to the modern theory of directed technical change (see, Acemoglu (2009), Chapter 15, for a recent survey). Here, the first contribution allowing for endogenous capital- and labor-saving technical change is Acemoglu (2003). Acemoglu's analytical setting extends the work of Romer (1990) by adding a research sector specialized in the discovery of new varieties of capital-intensive intermediates and intermediate-good monopolists that market these varieties. In contrast, the economy under scrutiny here is competitive. Innovation investments that increase the productivity of capital or the productivity of labor are financed through inframarginal rents. ${ }^{7}$ As will become clear below, this analytical framework avoids scale effects and, therefore, lends itself in a straightforward way to an analysis of the effects of demographic change on economic growth.

Second, the present paper contributes to a large and growing literature on the economic consequences of population aging in endogenous growth economies. Here, it is closest to contributions that emphasize the link between population aging and technical change. This link has been studied in an AK - framework (see,

\footnotetext{
${ }^{7}$ The compatibility of innovation investments financed through inframarginal rents and competitive endogenous economic growth is established in Hellwig and Irmen (2001).
} 
e.g., Futagami and Nakajima (2001)), with costly innovation investments (see, e. g., Heer and Irmen (2009)), or in the framework of first-generation endogenous growth models (see, e. g., Prettner (2013)). ${ }^{8}$ However, to the best of my knowledge, my analysis is the first that studies the consequences of population aging in a context with endogenous capital- and labor-saving technical change. My results suggest that the long-run growth effects of population aging identified in the existing literature will be mitigated or even vanish when capital-saving technical change becomes feasible. The discussion of Section 6.1 clarifies why the inclusion of capital-saving technical change is crucial for this assessment.

Third, the present paper contributes to the literature on the prospective growthenhancing effect of an improved state of public health. A central focus of this branch is on the aging-education nexus and its role for economic growth: ${ }^{9}$ better health means a higher life expectancy, and human capital accumulates faster since individual investments in education become more profitable.

Other than this line of reasoning, my analysis emphasizes the role of firms as investors in the human capital of their workforce. As detailed in Section 3, laborsaving investments undertaken by firms have a straightforward interpretation as investments in the human capital of the workforce. In the same vein, the stock of labor-saving technological knowledge may be interpreted as the economy's stock of human capital. Then, if better health causes population aging, the relative scarcity of labor increases so that firms find it more attractive to raise the human capital of their workforce. Accordingly, the stock of human capital and, hence, the economy grow faster. A central question is then how this logic fares in the presence of endogenous capital-saving technical change. Indeed, through the latter channel population aging is found to induce less capital-saving technical progress. Hence, the stock of capital-saving technological knowledge grows slower. Since economic growth reflects the growth of both stocks of knowledge, the net effect of population aging on growth remains undetermined. However, as explained earlier, in steady state population aging cannot have an effect on the growth rate of the economy. Hence, in the long run a better public health cannot

\footnotetext{
${ }^{8} \mathrm{~A}$ second set of contributions with endogenous economic growth studies the political economy of population aging and economic growth. Here, population aging increases the weight of the elderly in the democratic voting processes. This leads governments to favor policies in line with the consumptive needs of the old rather than growth promoting policies preferred by the young. As a consequence, population aging tends to be associated with slower economic growth (see, e. g., Kuehnel (2011) or Niepelt and Gonzalez-Eiras (2012)).

${ }^{9}$ See, e. g., de la Croix and Licandro (1999), Zhang, Zhang, and Lee (2001), Boucekkine, de la Croix, and Licandro (2002), Chakraborty (2004), Hazan and Zoabi (2006), Ashraf, Lester, and Weil (2009), and the empirical research cited in Footnote 3.
} 
cause faster economic growth.

Finally, the presnt paper also broadens and complements the theory of OLG models (de la Croix and Michel (2002)). Indeed, I show in Section 4.2 that the dynamical system with endogenous capital- and labor-saving technical change nests several other specifications. They include the economy where endogenous technical change must be labor-saving and the model of Diamond (1965), either with or without exogenous technical change.

\section{The Basic Model}

The economy has a household sector and a final-good sector in an infinite sequence of periods $t=1,2, \ldots, \infty$. The household sector comprises two-period lived individuals facing a survival probability. There are three objects of exchange. The manufactured final good can be consumed or invested. If invested it may either become future capital or serve as an input in current capital- or laborsaving investments. Households supply labor and capital. Labor is 'owned' by the young, the old own the capital stock. Capital is the only asset in the economy and, without loss of generality, fully depreciates after one period. ${ }^{10}$ Each period has markets for all three objects of exchange. The final good serves as numéraire.

\subsection{Households}

Individuals live for possibly two periods, young and old age. When young, they work, consume, and save. At the onset of old age, they face a survival probability $v \in(0,1)$. Survivors retire and consume their wealth. The population at $t$ consists of $L_{t}$ young and $v L_{t-1}$ old individuals. Due to births and other demographic factors, the amount of young individuals between two adjacent periods grows at rate $\lambda>(-1)$. For short, I shall refer to $\lambda$ as the fertility rate.

\footnotetext{
${ }^{10} \mathrm{My}$ setup is mute on the question as to who owns the infinitely-lived firms in the economy. As individual preferences are defined over the single consumption good of each period, property rights of firms do not matter for the equilibrium allocation. Moreover, I consider competitive equilibria where maximized per-period profits are zero such that the expected present discounted value of dividends associated with any ownership share is zero, too. It is well known that these considerations are not sufficient to exclude equilibria with bubbles since the number of potential traders is infinite in the OLG-framework (Tirole (1985)). In what follows, I disregard this possibility and focus on equilibria without bubbles.
} 
Young individuals are endowed with a labor endowment equal to unity. It is inelastically supplied to the labor market. Hence, $L_{t}$ is the labor supply at $t$ and $\lambda$ its growth rate. The OADR at $t$ is then

$$
O A D R_{t} \equiv \frac{v L_{t-1}}{L_{t}}=\frac{v}{1+\lambda}
$$

According to this measure, there is population aging between period $t-1$ and $t$ if $O A D R_{t}>O A D R_{t-1}$. A decline in the fertility rate of generation $t-1$ and/or an increase in the survival probability of this generation leads to population aging.

Preferences of a member of cohort $t$ are homothetic and defined over the level of consumption when young and old, $c_{t}^{y}$ and $c_{t+1}^{o}$, respectively. Normalizing $u(0)=$ 0 to be the utility after death, expected lifetime utility is

$$
U_{t}=u\left(c_{t}^{y}\right)+v u\left(c_{t+1}^{o}\right)
$$

where $u: \mathbb{R}_{+} \rightarrow \mathbb{R}$ is a per-period utility function. It is $\mathcal{C}^{2}$ on $\mathbb{R}_{++}$and satisfies $u^{\prime}(c)>0>u^{\prime \prime}(c)$ as well as $\lim _{c \rightarrow 0} u^{\prime}(c)=\infty$.

I follow, e. g., Yaari (1965) or Blanchard (1985), and assume a perfect annuity market for insurance against survival risk. At the end of their young age, individuals of cohort $t$ deposit their entire savings with mutual funds. These funds rent savings out as capital to the firms producing in $t+1$. The latter pay a real rental rate $R_{t+1}$ per unit of capital. Perfect competition among mutual funds assures a gross return to a surviving old at $t+1$ of $R_{t+1} / v$. This rate exceeds the rental rate of capital and compensates individuals for the risk of dying before having their savings withdrawn.

Hence, the maximization of (3.2) is subject to the per-period budget constraints

$c_{t}^{y}+s_{t} \leq w_{t}$ and $c_{t+1}^{o} \leq s_{t} R_{t+1} / v$, where $s_{t}$ denotes savings and $w_{t}$ the real wage at $t$. Given the vector of prices, $\left(w_{t}, R_{t+1}\right) \in \mathbb{R}_{++}^{2}$, standard arguments reveal that the optimal plan of a member of cohort $t,\left(c_{t}^{y}, s_{t}, c_{t+1}^{o}\right)$, includes a continuous and partially differentiable function

$$
s_{t}=s\left(R_{t+1}, v\right) w_{t}, \quad \text { with } \quad s_{R}\left(R_{t+1}, v\right) \gtreqless 0 \quad \text { and } \quad s_{v}\left(R_{t+1}, v\right)>0 .
$$

\subsection{Firms}

At all $t$, the production sector has a continuum $[0,1]$ of competitive firms. Without loss of generality, their behavior may be analyzed through the lens of a competitive representative firm. To save on heavy notation, I shall use this perspective throughout the analysis if not indicated otherwise. 


\subsubsection{Technology}

Two types of tasks have to be performed to produce output. The first type needs capital, the second labor as the only input. Let $m \in \mathbb{R}_{+}$index a task performed by capital and $n \in \mathbb{R}_{+}$a task performed by labor. With $m_{t}$ and $n_{t}$ denoting the total 'number' of tasks of each type performed at $t$, I have $m \in\left[0, m_{t}\right]$ and $n \in\left[0, n_{t}\right]$. The production function $F: \mathbb{R}_{+}^{2} \rightarrow \mathbb{R}_{+}$assigns the maximum output, $Y_{t}$, to each pair $\left(m_{t}, n_{t}\right) \in \mathbb{R}_{+}^{2}$, i. e.,

$$
Y_{t}=F\left(m_{t}, n_{t}\right) .
$$

The function $F$ is $\mathcal{C}^{2}$ on $\mathbb{R}_{++}^{2}$ with $F_{1}>0>F_{11}$ and $F_{2}>0>F_{22}$. Moreover, it exhibits constant returns to scale with respect to both task types. ${ }^{11}$ For further reference, let $\kappa_{t}$ denote the period- $t$ task intensity of the firm, i. e.,

$$
\kappa_{t}=\frac{m_{t}}{n_{t}}
$$

The production function in intensive form is then $F\left(\kappa_{t}, 1\right) \equiv f\left(\kappa_{t}\right)$, where $f$ : $\mathbb{R}_{+} \rightarrow \mathbb{R}_{+}$, with $f^{\prime}\left(\kappa_{t}\right)>0>f^{\prime \prime}\left(\kappa_{t}\right)$ for all $\kappa_{t}>0$.

At $t$, a task $m$ requires $k_{t}(m)=1 / b_{t}(m)$ units of capital, a task $n$ needs $l_{t}(n)=$ $1 / a_{t}(n)$ units of labor. Hence, $b_{t}(m)$ and $a_{t}(n)$ denote the productivity of capital and labor, respectively. They are equal to

$$
\begin{aligned}
& b_{t}(m)=B_{t-1}(1-\delta)\left(1+q_{t}^{B}(m)\right), \\
& a_{t}(n)=A_{t-1}(1-\delta)\left(1+q_{t}^{A}(n)+\eta^{A} e_{t}^{A}\right) ;
\end{aligned}
$$

here $B_{t-1}$ and $A_{t-1}$ denote aggregate indicators of the level of technological knowledge at $t-1$, and $\delta \in(0,1)$ is the rate of depreciation of technological knowledge between any pair of periods $t-1$ and $t$. Accordingly, the terms $B_{t-1}(1-\delta)$ and $A_{t-1}(1-\delta)$ represent the level of technological knowledge to which the firm at $t$ has access for free. Then, $q_{t}^{B}(m) \in \mathbb{R}_{+}$and $q_{t}^{A}(n) \in \mathbb{R}_{+}$are indicators of productivity growth associated with task $m$ and task $n$, respectively. Finally, the productivity of labor in task $n$ hinges on an external effect, $e_{t}^{A} \geq 0$. It captures contemporaneous knowledge spill-overs associated with the creation of laborsaving technical change. This externality is equal to the average productivity growth rates achieved in all tasks using labor, i. e.,

$$
e_{t}^{A} \equiv \frac{1}{n_{t}} \int_{0}^{n_{t}} q_{t}^{A}(n) d n
$$

\footnotetext{
${ }^{11}$ To include, e.g., the CES production function, I make no assumptions on the limits of the function $F$ and its derivatives for $m_{t} \rightarrow 0, n_{t} \rightarrow 0, m_{t} \rightarrow \infty$, and $n_{t} \rightarrow \infty$.
} 
The parameter $\eta^{A} \in \mathbb{R}_{+}$measures its strength.

To achieve productivity growth rates $q_{t}^{B}(m)>0$ and $q_{t}^{A}(n)>0$, the firm must invest $i\left(q_{t}^{B}(m)\right)>0$ and $i\left(q_{t}^{A}(n)\right)>0$ units of final output in period $t$. To fix ideas, suppose that a task has to be performed by a mainframe computer that is part of a firm's capital stock. Then, any equipment investment that reduces the time this computer needs to accomplish the task in question generates capitalsaving technical change. Similarly, for a task performed by labor, one may think of labor-saving technical change as the result of an equipment investment that reduces the amount of time a worker needs to accomplish the considered task. Alternatively, labor-saving technical change may reflect investments of the firm in the human capital of its workforce. As, e.g., in Lucas (1988), the creation of human capital motivates the presence of the positive external effect whenever $\eta^{A}>0$.

The function $i: \mathbb{R}_{+} \rightarrow \mathbb{R}_{+}$is the same for all tasks, time invariant, $\mathcal{C}^{2}$ on $\mathbb{R}_{++}$, increasing and strictly convex. Hence, higher rates of productivity growth require ever larger investments. Moreover, with the notation $i^{\prime}\left(q^{j}\right) \equiv d i\left(q^{j}\right) / d q^{j}$ for $j=A, B$, it satisfies

$$
i(0)=0, \quad \lim _{q^{j} \rightarrow 0} i^{\prime}\left(q^{j}\right)=0, \quad \text { and } \quad \lim _{q^{j} \rightarrow \infty} i^{\prime}\left(q^{j}\right)=\infty .
$$

At the level of the individual firm, I assume that any new piece of technological knowledge is proprietary knowledge of an investing firm only in $t$, i.e., in the period when it occurs. Subsequently, the advancement of technological knowledge becomes embodied in aggregate task specific productivity indicators $\left(A_{t}, B_{t}\right),\left(A_{t+1}, B_{t+1}\right), \ldots$, with no further scope for proprietary exploitation. The evolution of these indicators will be specified below. If the firm decides not to make an investment for a task $m$ or $n$ then it has access to the production technique represented by $A_{t-1}(1-\delta)$ and $B_{t-1}(1-\delta)$ such that $a_{t}(n)=A_{t-1}(1-\delta)$ and $b_{t}(m)=B_{t-1}(1-\delta)$.

\subsubsection{Profit-Maximization}

The firm takes the sequence $\left\{w_{t}, R_{t}, A_{t-1}, B_{t-1}, e_{t}^{A}\right\}_{t=1}^{\infty}$ of real wages, real rental rates of capital, of aggregate productivity indicators, and of the knowledge externality as given and chooses a production plan $\left(m_{t}, n_{t}, k_{t}(m), l_{t}(n), q_{t}^{B}(m), q_{t}^{A}(n)\right)$ for $m \in\left[0, m_{t}\right], n \in\left[0, n_{t}\right]$ and all $t$. This plan maximizes the sum of the present discounted values of profits in all periods. Since an investment generates proprietary knowledge only in the period when it is made, the inter-temporal maximization boils down to the maximization of per-period profits. Hence, for each 
period $t$, the firm needs to find the plan that maximizes turnover minus total costs

$$
\begin{aligned}
\Pi_{t} & =F\left(m_{t}, n_{t}\right)-C_{t} \\
C_{t} & =\int_{0}^{m_{t}}\left[R_{t} k_{t}(m)+i\left(q_{t}^{B}(m)\right)\right] d m+\int_{0}^{n_{t}}\left[w_{t} l_{t}(n)+i\left(q_{t}^{A}(n)\right)\right] d n ;
\end{aligned}
$$

here, $C_{t}$ sums up the costs per task of both task types. With (3.6) I have $k_{t}(m)=\frac{1}{B_{t-1}(1-\delta)\left(1+q_{t}^{B}(m)\right)} \quad$ and $\quad l_{t}(n)=\frac{1}{A_{t-1}(1-\delta)\left(1+q_{t}^{A}(n)+\eta^{A} e_{t}^{A}\right)}$.

Therefore, at all $t=1,2, \ldots, \infty$, the firm's problem may be split up in two parts. First, it chooses for each $n \in\left[0, n_{t}\right]$ and $m \in\left[0, m_{t}\right]$ the values $\left(q_{t}^{A}(n), q_{t}^{B}(m)\right) \in$ $\mathbb{R}_{+}^{2}$ that minimize $C_{t}$. Second, it determines the number of tasks $\left(n_{t}, m_{t}\right) \in \mathbb{R}_{+}^{2}$ that maximize $\Pi_{t}$. The respective first-order (sufficient) conditions for an interior solution are ${ }^{12}$

$$
\begin{aligned}
q_{t}^{A}(n) & : \frac{-w_{t}}{A_{t-1}(1-\delta)\left(1+q_{t}^{A}(n)+\eta^{A} e_{t}^{A}\right)^{2}}+i^{\prime}\left(q_{t}^{A}(n)\right)=0, \quad \forall n \in\left[0, n_{t}\right] \\
q_{t}^{B}(m) & : \frac{-R_{t}}{B_{t-1}(1-\delta)\left(1+q_{t}^{B}(m)\right)^{2}}+i^{\prime}\left(q_{t}^{B}(m)\right)=0, \quad \forall m \in\left[0, m_{t}\right] \\
n_{t} & : f\left(\kappa_{t}\right)-\kappa_{t} f^{\prime}\left(\kappa_{t}\right)-i\left(q_{t}^{A}\left(n_{t}\right)\right)-\frac{w_{t}}{a_{t}\left(n_{t}\right)}=0 \\
m_{t} & : f^{\prime}\left(\kappa_{t}\right)-i\left(q_{t}^{B}\left(m_{t}\right)\right)-\frac{R_{t}}{b_{t}\left(m_{t}\right)}=0 .
\end{aligned}
$$

For each task of the respective type, conditions (3.9) and (3.10) equate the marginal reduction of the firm's wage bill/capital cost to the marginal increase in its investment costs. Hence, these conditions assure that each task is performed at minimum cost. Assuming $w_{t}>0$ and $R_{t}>0$, the convexity of the innovation cost function and the fact that $\lim _{q^{j} \rightarrow 0} i^{\prime}\left(q^{j}\right)=0, j=A, B$, imply that these conditions determine a unique $q_{t}^{A}(n)=q_{t}^{A}>0$ and $q_{t}^{B}(m)=q_{t}^{B}>0$ for either task type. Accordingly, $a_{t}(n)=a_{t}, b_{t}(m)=b_{t}$, and $e_{t}^{A}=q_{t}^{A} \cdot{ }^{13}$

\footnotetext{
${ }^{12}$ Sufficiency follows since $\Pi_{t}$ is strictly concave in $\left(q_{t}^{A}(n), q_{t}^{B}(m)\right)$ and exhibits constant returns to scale in $\left(n_{t}, m_{t}\right)$ at the cost minimizing choices.

${ }^{13}$ Upon dividing (3.9) by (3.10) and rearranging reveals that the incentives to minimize (total) costs constitute an essential part of Hicks' conjecture quoted in Footnote 4. Indeed, one obtains $w_{t} / R_{t}=A_{t-1}\left(1+\left(1+\eta^{A}\right) q_{t}^{A}\right)^{2} i^{\prime}\left(q_{t}^{A}\right) /\left[B_{t-1}\left(1+q_{t}^{B}\right)^{2} i^{\prime}\left(q_{t}^{B}\right)\right]$. Since the numerator of the right-hand side increases in $q_{t}^{A}$ and the denominator increases in $q_{t}^{B}$, an increase in the relative price of labor induces, ceteris paribus, relatively more labor-saving technical change, i.e., a hike in $w_{t} / R_{t}$ means a greater ratio $q_{t}^{A} / q_{t}^{B}$.
} 
Conditions (3.11) and (3.12) assure that the number of tasks of each type is chosen optimally. For the marginal task it must hold that the difference between its value product and its cost vanishes. The former is expressed in terms of the task intensity, the latter is the sum of the investment outlays and the wage, respectively capital cost of the marginal task.

Observe that $\Pi_{t}$ has constant returns to scale in $\left(m_{t}, n_{t}\right)$ at $q_{t}^{A}(n)=q_{t}^{A}$ and $q_{t}^{B}(m)=q_{t}^{B}$. Therefore, conditions (3.11) and (3.12) leave the number of tasks undetermined. They will be pinned down by market clearing conditions. For the same reason, profit-maximization implies zero profits. Combining the first-order conditions at the optimum delivers the following important result.

Lemma 1 If (3.9) - (3.12) hold at $t$, then there are maps, $g^{A}: \mathbb{R}_{++}^{2} \rightarrow \mathbb{R}_{++}$and $g^{B}: \mathbb{R}_{++} \rightarrow \mathbb{R}_{++}$, such that $q_{t}^{A}=g^{A}\left(\kappa_{t}, \eta^{A}\right)$ and $q_{t}^{B}=g^{B}\left(\kappa_{t}\right)$ satisfy

$$
g_{\mathcal{K}}^{A}\left(\kappa_{t}, \eta^{A}\right)>0>g_{\mathcal{K}}^{B}\left(\kappa_{t}\right) \text { and } g_{\eta^{A}}^{A}\left(\kappa_{t}, \eta^{A}\right)<0 \quad \text { for all } \kappa_{t}>0
$$

Moreover, there are maps $w: \mathbb{R}_{++}^{2} \rightarrow \mathbb{R}_{++}$and $R: \mathbb{R}_{++}^{2} \rightarrow \mathbb{R}_{++}$, such that the real wage and the rental rate of capital satisfy

$$
\begin{aligned}
& w_{t}=w\left(\kappa_{t}, A_{t-1}\right)>0, \text { with } w_{\mathcal{K}}\left(\kappa_{t}, A_{t-1}\right)>0, \quad w_{A}\left(\kappa_{t}, A_{t-1}\right)>0, \\
& R_{t}=R\left(\kappa_{t}, B_{t-1}\right)>0, \quad \text { with } \quad R_{\kappa}\left(\kappa_{t}, B_{t-1}\right)<0, \quad R_{B}\left(\kappa_{t}, B_{t-1}\right)>0 .
\end{aligned}
$$

Lemma 1 states two key properties of the production sector. First, the equilibrium incentives to engage in labor- and capital-saving technical change depend on the task intensity. The incentive to engage in labor-saving technical change increases with this intensity, the incentive to engage in capital-saving technical change decreases with it. Moreover, the positive externality reduces the incentives to invest in labor-saving technical change. Second, factor prices may be expressed as a function of the task intensity and the respective technology indicators, $A_{t-1}$ and $B_{t-1} \cdot{ }^{14}$ While the real wage increases with the task intensity, the real rental rate of capital declines with it. Both factor prices increase in the technology indicators.

Intuitively, the effect of changing $\kappa_{t}$ on investment incentives and factor prices reflects two sides of the same coin. To see this, consider a triple $\left(\kappa_{t}, g^{A}\left(\kappa_{t}, \eta^{A}\right), w_{t}\right)$ that satisfies (3.9) and (3.11). As shown in Figure 3.1, for these values the cost per task is minimized (right panel) and this minimum is equal to the marginal

\footnotetext{
${ }^{14}$ One readily verifies that the function $w$ also depends on $\eta^{A}$ with $w_{\eta^{A}}$ being indeterminate in general. Since this argument is of little interest for what follows I shall suppress it.
} 
Figure 3.1: The Link between $\kappa_{t}, q_{t}^{A}=g^{A}\left(\kappa_{t}, \eta^{A}\right)$ and $w_{t}$.

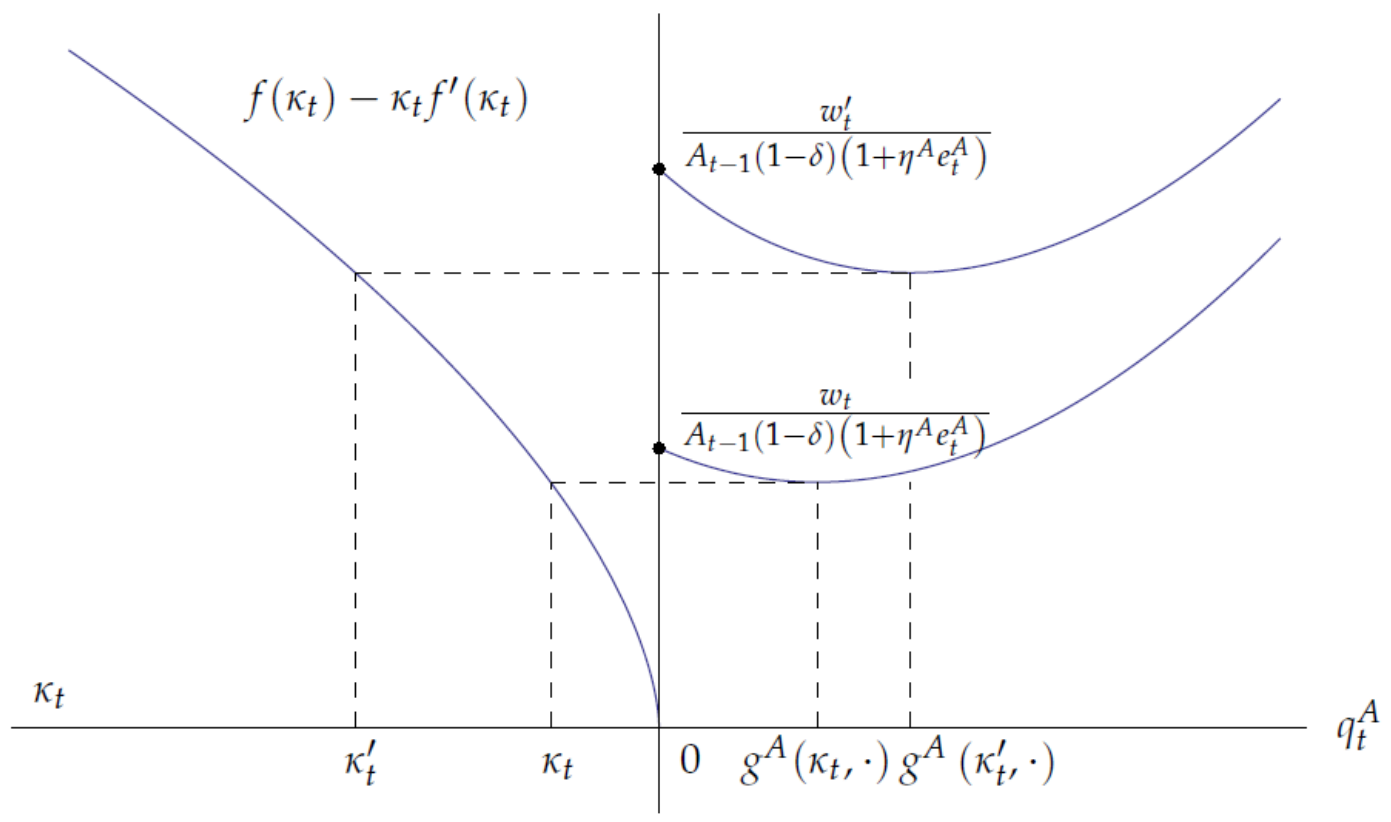

value product of task $n_{t}$ (left panel). The latter increases as $\kappa_{t}$ shifts to $\kappa_{t}^{\prime}$ so that the minimum cost of task $n_{t}$ must increase. This requires the higher wage $w_{t}^{\prime}$, hence $w_{\kappa}\left(\kappa_{t}, A_{t-1}\right)>0$. At $w_{t}^{\prime}$, the marginal benefit of faster productivity growth is higher. Therefore, the minimum cost is attained at a higher $q_{t}^{A}$, hence $g_{\kappa}^{A}\left(\kappa_{t}, \eta^{A}\right)>0$. The effect of $\kappa_{t}$ on $R_{t}$ and $q_{t}^{B}$ may be derived in an analogous manner. However, in this case an increase in $\kappa_{t}$ reduces the marginal value product of task $m_{t}$ in (3.12). Therefore $R_{t}$ must decline, and so does $q_{t}^{B}$ in accordance with (3.10). Hence, $R_{\kappa}\left(\kappa_{t}, B_{t-1}\right)<0$ and $g_{\kappa}^{B}\left(\kappa_{t}\right)<0$.

Finally, note that the external effect increases in $\eta^{A}$. Therefore, a larger $\eta^{A}$ weakens the marginal cost advantage of labor-saving innovation investments. Accordingly, the cost per task reaches its minimum at a lower level of $q_{t}^{A}$. This explains why $g_{\eta^{A}}^{A}\left(\kappa_{t}, \eta^{A}\right)<0$

\subsection{The Evolution of Technological Knowledge}

The evolution of the economy's level of technological knowledge is given by the evolution of the aggregate task specific productivity indicators $A_{t}$ and $B_{t}$. An important question is then how these indicators are linked to the productivity enhancing investments associated with all performed tasks. In what follows I 
associate the highest level of labor and capital productivity attained across all tasks of a respective type with $A_{t}$ and $B_{t}$, i. e.,

$$
\begin{aligned}
& A_{t}=\max \left\{a_{t}(n)=A_{t-1}(1-\delta)\left(1+q_{t}^{A}(n)+\eta^{A} e_{t}^{A}\right) \mid n \in\left[0, n_{t}\right]\right\} \\
& B_{t}=\max \left\{b_{t}(m)=B_{t-1}(1-\delta)\left(1+q_{t}^{B}(m)\right) \mid m \in\left[0, m_{t}\right]\right\} .
\end{aligned}
$$

Since profit-maximization implies $q_{t}^{A}(n)=q_{t}^{A}=e_{t}^{A}, q_{t}^{B}(m)=q_{t}^{B}, a_{t}(n)=a_{t}$, and $b_{t}(m)=b_{t}$, I have

$$
\begin{aligned}
& A_{t}=a_{t}=A_{t-1}(1-\delta)\left(1+\left(1+\eta^{A}\right) q_{t}^{A}\right) \\
& B_{t}=b_{t}=B_{t-1}(1-\delta)\left(1+q_{t}^{B}\right)
\end{aligned}
$$

for all $t=1,2, \ldots, \infty$, with $A_{0}>0$ and $B_{0}>0$ as initial conditions.

\section{Inter-temporal General Equilibrium}

\subsection{Definition}

A price system corresponds to a sequence $\left\{w_{t}, R_{t}\right\}_{t=1}^{\infty}$. An allocation is a sequence

$$
\left\{c_{t}^{y}, s_{t}, c_{t}^{o}, Y_{t}, n_{t}, m_{t}, q_{t}^{A}(n), q_{t}^{B}(m), a_{t}(n), b_{t}(m), l_{t}(n), k_{t}(m), e_{t}^{A}, L_{t}, K_{t}\right\}_{t=1}^{\infty}
$$

for all tasks $n \in\left[0, n_{t}\right]$ and $m \in\left[0, m_{t}\right]$. It comprises a strategy $\left\{c_{t}^{y}, s_{t}, c_{t+1}^{o}\right\}_{t=1}^{\infty}$ for all cohorts, consumption of the old at $t=1, c_{1}^{o}$, and a strategy for the production sector $\left\{Y_{t}, n_{t}, m_{t}, q_{t}^{A}(n), q_{t}^{B}(m), a_{t}(n), b_{t}(m), l_{t}(n), k_{t}(m)\right\}_{t=1}^{\infty}$.

For an exogenous evolution of the labor force, $L_{t}=L_{1}(1+\lambda)^{t-1}$ with $L_{1}>0$ and $\lambda>(-1)$, a given survival probability $v$ for all cohorts, a given $\eta^{A}$, a given initial level of capital, $K_{1}>0$, and initial values of technological knowledge, $A_{0}>0$ and $B_{0}>0$, an inter-temporal general equilibrium with perfect foresight corresponds to a price system, an allocation, and a sequence $\left\{A_{t}, B_{t}\right\}_{t=1}^{\infty}$ of aggregate productivity indicators that satisfy the following conditions for all $t=1,2, \ldots, \infty$ :

(E1) The young of each period save according to (3.3) and supply $L_{t}$ units of labor.

(E2) The production sector satisfies Lemma 1. 
(E3) The market for the final good clears, i. e.,

$$
v L_{t-1} c_{t}^{o}+L_{t} c_{t}^{y}+I_{t}^{K}+I_{t}^{A}+I_{t}^{B}=Y_{t},
$$

where $I_{t}^{K}$ is aggregate capital investment, $I_{t}^{A}$ and $I_{t}^{B}$ denote aggregate innovation investments in labor- and capital-saving technical change.

(E4) There is full employment of labor and capital, i.e.,

$$
\int_{0}^{n_{t}} l_{t}(n) d n=L_{t} \quad \text { and } \quad \int_{0}^{m_{t}} k_{t}(m) d m=K_{t} .
$$

(E5) The productivity indicators $A_{t}$ and $B_{t}$ evolve according to (3.16).

(E1) guarantees optimal behavior of the household sector under perfect foresight. Since the surviving old own the capital stock, their consumption at $t=1$ is $v L_{0} c_{1}^{o}=R_{1} K_{1}$. (E2) assures optimal behavior of the production sector and zero profits. (E3) states the resource constraint in (4.1). It reflects the fact that capital fully depreciates after one period.

Full employment of labor and capital, i. e., condition (E4), and Lemma 1 imply that in equilibrium

$$
\begin{aligned}
n_{t}=a_{t} L_{t} \quad \text { and } \quad m_{t}=b_{t} K_{t}, \\
I_{t}^{A}=a_{t} L_{t} i\left(q_{t}^{A}\right) \quad \text { and } \quad I_{t}^{B}=b_{t} K_{t} i\left(q_{t}^{B}\right),
\end{aligned}
$$

i. e., for each task type the number of performed tasks is equal to the respective input in efficiency units. In other words, technical change is factor augmenting and $Y_{t}=F\left(b_{t} K_{t}, a_{t} L_{t}\right)$. Moreover, aggregate investment in labor- and capital-saving technical change is proportionate to the respective input in efficiency units.

Observe that the task intensity of (3.5) and the full employment condition (4.3) imply that $\kappa_{t}=m_{t} / n_{t}=b_{t} K_{t} / a_{t} L_{t}$. Hence, in equilibrium the task intensity is equal to the 'efficient capital intensity' defined as the amount of efficient capital per unit of efficient labor. However, from Lemma 1 the efficient capital intensity itself depends on the task intensity, i.e.,

$$
\kappa_{t}=\frac{B_{t-1}\left(1+g^{B}\left(\kappa_{t}\right)\right) K_{t}}{A_{t-1}\left(1+\left(1+\eta^{A}\right) g^{A}\left(\kappa_{t}, \eta^{A}\right)\right) L_{t}} .
$$

Therefore, I have to make sure that a value $\kappa_{t}>0$ exists that satisfies (4.5). To address this issue, denote by

$$
\begin{aligned}
\varepsilon_{\mathcal{\kappa}}^{A}\left(\kappa_{t}, \eta^{A}\right) & \equiv \frac{d \ln \left(1+\left(1+\eta^{A}\right) g^{A}\left(\kappa_{t}, \eta^{A}\right)\right)}{d \ln \kappa_{t}}>0, \\
\varepsilon_{\mathcal{\kappa}}^{B}\left(\kappa_{t}\right) & \equiv \frac{-d \ln \left(1+g^{B}\left(\kappa_{t}\right)\right)}{d \ln \kappa_{t}}>0
\end{aligned}
$$


the elasticities of the respective productivity growth factors with respect to the efficient capital intensity.

Lemma 2 There is a map $\kappa: \mathbb{R}_{++} \rightarrow \mathbb{R}_{++}$such that

$$
\kappa_{t}=\kappa\left(\frac{B_{t-1} K_{t}}{A_{t-1} L_{t}}\right)>0
$$

satisfies (4.5). Moreover,

$$
\varepsilon^{\kappa}\left(\kappa_{t}\right) \equiv \frac{d \ln \kappa_{t}}{d \ln \left(K_{t} / L_{t}\right)}=\frac{1}{1+\varepsilon_{\mathcal{\kappa}}^{A}\left(\kappa_{t}, \eta^{A}\right)+\varepsilon_{\mathcal{K}}^{B}\left(\kappa_{t}\right)} \in(0,1)
$$

Hence, there is a unique solution $\kappa_{t}>0$ to (4.5). ${ }^{15}$ Moreover, an increase in the capital-labor ratio, $K_{t} / L_{t}$, implies a higher efficient capital intensity. Due to induced innovation investments, this increase is less than proportionate.

\subsection{The Dynamical System}

The equilibrium conditions (E1) - (E5) require savings to equal capital investment, i.e.,

$$
I_{t}^{K}=s_{t} L_{t}=K_{t+1}, \quad \text { for } t=1,2, \ldots, \infty .
$$

The evolution of the economy may then be characterized by means of two state variables, namely the efficient capital intensity, $\kappa_{t}$, and the level of the aggregate productivity indicator $B_{t}$. Let $\tilde{w}\left(\kappa_{t}\right) \equiv w\left(\kappa_{t}, A_{t-1}\right) / a_{t}$ denote the real wage per efficiency unit. Moreover, use (3.3), (3.14), and (4.5) to define the elasticities

$$
\varepsilon_{R}^{s}\left(\kappa_{t}\right) \equiv \frac{d \ln s\left(R\left(\kappa_{t}, B_{t-1}\right), v\right)}{d \ln R_{t}} \gtreqless 0, \quad \text { and } \quad \varepsilon_{\mathcal{K}}^{R}\left(\kappa_{t}\right) \equiv \frac{d \ln R\left(\kappa_{t}, B_{t-1}\right)}{d \ln \kappa_{t}}<0 .
$$

With $\varepsilon\left(\kappa_{t+1}\right) \equiv\left[\varepsilon_{R}^{s}\left(\kappa_{t+1}\right)\right]\left[\varepsilon_{\mathcal{K}}^{R}\left(\kappa_{t+1}\right)\right]\left[\varepsilon^{\mathcal{K}}\left(\kappa_{t+1}\right)\right]$, the dynamical system may be stated as follows.

Proposition 1 Given $\left(K_{1}, L_{1}, A_{0}, B_{0}\right)>0$ as initial conditions, there is a unique equilibrium sequence $\left\{\kappa_{t}, B_{t}\right\}_{t=1}^{\infty}$ determined by

$$
\frac{s\left(R\left(\kappa_{t+1}, B_{t}\right), v\right)}{1+\lambda} \tilde{w}\left(\kappa_{t}\right)=\frac{\kappa_{t+1}}{B_{t}} \frac{1+\left(1+\eta^{A}\right) g^{A}\left(\kappa_{t+1}, \eta^{A}\right)}{1+g^{B}\left(\kappa_{t+1}\right)},
$$

\footnotetext{
${ }^{15}$ For ease of notation, the dependency of the functions $\kappa(\cdot)$ and $\varepsilon^{\kappa}(\cdot)$ on $\eta^{A}$ is suppressed in the main text.
} 
and

$$
B_{t}=B_{t-1}(1-\delta)\left(1+g^{B}\left(\kappa_{t}\right)\right)
$$

if

$$
\varepsilon\left(\kappa_{t+1}\right)<1 \text { for all } \kappa_{t+1}>0
$$

For $t=1, \kappa_{1}$ is given by

$$
\kappa_{1}=\frac{B_{0}\left(1+g^{B}\left(\kappa_{1}\right)\right) K_{1}}{A_{0}\left(1+\left(1+\eta^{A}\right) g^{A}\left(\kappa_{1}, \eta^{A}\right)\right) L_{1}}>0 .
$$

Hence, the dynamical system may be stated as a two-dimensional system of firstorder, autonomous, non-linear difference equations. The equation of motion for the efficient capital intensity is (4.9). It restates the condition for savings to equal capital investment, i. e., (4.8), where $K_{t+1}$ is replaced by an update of (4.5). For any given pair $\left(\kappa_{t}, B_{t}\right) \in \mathbb{R}_{++}^{2},(4.9)$ assigns a unique value $\kappa_{t+1}>0$ if (4.11) holds. This value of $\kappa_{t+1}$ is then used to derive $B_{t+1}$ from (4.10). Since $K_{1}, L_{1}, A_{0}$, and $B_{0}$ are initial conditions, $\kappa_{1}$ is pinned down by (4.5) for $t=1$.

Observe that the dynamical system of Proposition 1 nests several OLG-models with either endogenous or exogenous economic growth. For instance, the case of an economy that allows only for endogenous labor-saving technical change obtains if I fix $q_{t}^{B}(m)=0$ and $b_{t}=B_{t}=B>0$ for all $t$. I discuss this case in Section 6.1 to further elucidate the role of endogenous capital-saving technical change. Assuming in addition that labor productivity growth is given by some exogenous $q^{A}>(-1)$ for all $t$ and costless, i. e., setting $i\left(q^{A}\right)=0$, turns the production side into the one of the neoclassical growth model with exogenous labor-saving technical change. Then, with $B=1$, equations (4.9) and (4.12) reduce, respectively, to

$$
\frac{s\left(R\left(\kappa_{t+1}\right), v\right)}{1+\lambda} \tilde{w}\left(\kappa_{t}\right)=\kappa_{t+1}(1-\delta)\left(1+\left(1+\eta^{A}\right) q^{A}\right)
$$

and

$$
\kappa_{1}=\frac{K_{1}}{L_{1} A_{0}(1-\delta)\left(1+\left(1+\eta^{A}\right) q^{A}\right)} .
$$

If, in addition, $q^{A}=\delta /\left[(1-\delta)\left(1+\eta^{A}\right)\right]$, then $A_{t}=A_{0}$ for all $t$ and (4.9) collapses to Diamond's difference equation for the capital intensity (Diamond (1965)). 
From this perspective, condition (4.11), which states the permissible percentage change of the savings rate induced by an increase in $K_{t+1} / L_{t+1}$ at $\kappa_{t+1}$, may be seen as a generalization of a condition for the existence and the uniqueness of the inter-temporal equilibrium under perfect foresight in an OLG-economy without technical change (see, e.g., de la Croix and Michel (2002), p. 20 ff.). It allows for the savings rate to decline in response to an increase in the rental rate of capital. However, this decline must not be too pronounced.

\section{Population Aging and Economic Growth}

Now, I turn to the implications of the preceding results for the relationship between population aging and economic growth. I start with the short-run implications before I turn to the long run.

\subsection{Population Aging and Economic Growth in the Short-Run}

By definition, the short-run effects of population aging arise if the old-age dependency ratio increases between two adjacent periods. Taking the fertility and the mortality channel separately, this is either due to a decline in the fertility of the young of the first of these periods and/or to an (anticipated) increase in their survival probability. Both demographic changes increase the old-age dependency ratio in the second of the two periods. The following proposition compares the evolution of two initially identical economies that experience differing patterns of population aging between $t$ and $t+1$.

Proposition 2 Consider two economies with identical initial conditions $\left(K_{t}, L_{t}, A_{t-1}, B_{t-1}\right)$ at some period $t \geq 1$. If the cohorts t of these economies have different fertility rates, $\lambda>$ $\lambda^{\prime}$, and/or different survival probabilities, $v^{\prime}>v$, then $\left(K_{t+1} / L_{t+1}\right)^{\prime}>K_{t+1} / L_{t+1}$. Moreover,

$$
\left(q_{t+1}^{A}\right)^{\prime}>q_{t+1}^{A}, \quad\left(q_{t+1}^{B}\right)^{\prime}<q_{t+1}^{B}, \quad w_{t+1}^{\prime}>w_{t+1}, \quad \text { and } \quad R_{t+1}^{\prime}<R_{t+1} .
$$

According to Proposition 2 it is the 'older' economy that has a greater capitallabor ratio in $t+1$. Therefore, it experiences faster labor-saving technical change and slower capital-saving technical change. Moreover, its real wage is higher and its real rental rate of capital is lower. 
The intuition for these results comes in two steps. The first step concerns the inter-temporal channel through which population aging affects the capital-labor ratio. It justifies why $\left(K_{t+1} / L_{t+1}\right)^{\prime}>K_{t+1} / L_{t+1}$. To see this, consider the capital accumulation equation (4.8). With savings of (3.3), Lemma 1, and Lemma 2 it can be expressed in terms of $K_{t+1} / L_{t+1}, \lambda$, and $v$. For periods $t$ and $t+1$ this gives

$$
\frac{s\left(R\left(\kappa\left(\frac{B_{t} K_{t+1}}{A_{t} L_{t+1}}\right), B_{t}\right), v\right)}{1+\lambda} w_{t}=\frac{K_{t+1}}{L_{t+1}} .
$$

Hence, for a given savings rate, a lower $\lambda$ requires a larger capital-labor ratio in $t+1$. However, anticipating this and the ensuing implications for the efficient task intensity and the real rental rate of capital, individuals adjust there savings behavior. ${ }^{16}$ Similarly, for a given real rental rate of capital, a higher survival probability implies a higher $K_{t+1} / L_{t+1}$. This induces an anticipated adjustment of the rental rate of capital and the savings rate. Total differentiation of (5.2) captures these repercussions and delivers

$$
\begin{aligned}
& \frac{\partial\left(K_{t+1} / L_{t+1}\right)}{\partial \lambda}=-\frac{s\left(R_{t+1}, v\right) w_{t} /(1+\lambda)^{2}}{1-\varepsilon}<0, \\
& \frac{\partial\left(K_{t+1} / L_{t+1}\right)}{\partial v}=\frac{s_{v}\left(R_{t+1}, v\right) w_{t} /(1+\lambda)}{1-\varepsilon}>0,
\end{aligned}
$$

where $\varepsilon$ is evaluated at $\kappa_{t+1}$. The signs follow since $\varepsilon<1$ and $s_{v}>0$. Hence, an increase in the OADR induced either by a decline in fertility and/or by an increase in the survival probability leads to a higher capital-labor ratio.

The second step reflects the static adjustments in $t+1$ to an increase in the capitallabor ratio. According to Lemma 2, the $\left(\lambda^{\prime}, v^{\prime}\right)$ - economy exhibits a greater efficient capital intensity, i.e., $\kappa_{t+1}^{\prime}>\kappa_{t+1}$. In accordance with Lemma 1, the latter induces the technology and price adjustments stated in (5.1). ${ }^{17}$

\footnotetext{
${ }^{16}$ There are at least two scenarios where this second channel is mute since savings do not respond to a changing rental rate of capital. First, this is the case if the inter-temporal elasticity of substitution is equal to one. Second, if expectations of generation $t$ are not rational but 'myopic' (Michel and de la Croix (2000)), then the expected rental rate of capital is $R_{t+1}=R\left(\kappa_{t}, B_{t-1}\right)$, i. e., savings in $t$ do not reflect changes of the economic environment that may happen between $t$ and $t+1$.

${ }^{17}$ Observe that both steps taken together provide a straightforward link between population aging and Hicks' contention mentioned in Footnote 4: population aging leads to a higher capitallabor ratio, i. e., the relative scarcity of labor increases. This induces a higher real wage, a lower real rental rate, more labor- and less capital-saving technical change.
} 
What are the implications of Proposition 2 for the growth rates of aggregate and per-capita income in aging economies? To address this question, let $V_{t}$ denote aggregate equilibrium income, or 'income' for short. Since $\Pi_{t}=0$ in equilibrium, income is equal to the difference between the output of the final good and total investment outlays. More precisely, from (3.8), the market-clearing conditions (4.3) and (4.4), I obtain

$$
V_{t} \equiv V\left(b_{t} K_{t}, a_{t} L_{t}\right)=F\left(b_{t} K_{t}, a_{t} L_{t}\right)-a_{t} L_{t} i\left(q_{t}^{A}\right)-b_{t} K_{t} i\left(q_{t}^{B}\right),
$$

and per-capita income at $t$ is $v_{t} \equiv V_{t} /\left(v L_{t-1}+L_{t}\right)$.

To prepare for the analysis of how population aging affects income growth, it is necessary to describe how changing factor supplies affect $V_{t}$ through induced technical change. I denote this channel by $E_{t}^{L}$ if it is due to a change in the labor force at $t$ and by $E_{t}^{K}$ if it is due to a change in the capital stock at $t$. Using (3.16) and Lemma 1 in (5.5) delivers

$$
\begin{aligned}
& E_{t}^{L}=\left[\frac{\partial V_{t}}{\partial q_{t}^{A}} g_{\mathcal{\kappa}}^{A}\left(\kappa_{t}, \eta^{A}\right)+\frac{\partial V_{t}}{\partial q_{t}^{B}} g_{\mathcal{K}}^{B}\left(\kappa_{t}\right)\right] \frac{\partial \kappa_{t}}{\partial L_{t}}, \\
& E_{t}^{K}=\left[\frac{\partial V_{t}}{\partial q_{t}^{A}} g_{\mathcal{K}}^{A}\left(\kappa_{t}, \eta^{A}\right)+\frac{\partial V_{t}}{\partial q_{t}^{B}} g_{\kappa}^{B}\left(\kappa_{t}\right)\right] \frac{\partial \kappa_{t}}{\partial K_{t}} .
\end{aligned}
$$

Since $g_{\mathcal{K}}^{A}\left(\kappa_{t}, \eta^{A}\right)>0>g_{\mathcal{K}}^{B}\left(\kappa_{t}\right)$, changing factor endowments induce technical adjustments of opposite sign. Nevertheless, the following lemma shows that these adjustments have unequivocal effects on income.

Lemma 3 In equilibrium, it holds that

$$
\frac{\partial V_{t}}{\partial q_{t}^{A}}=\frac{\eta^{A} w_{t} L_{t}}{1+\left(1+\eta^{A}\right) q_{t}^{A}}>0, \quad \text { and } \quad \frac{\partial V_{t}}{\partial q_{t}^{B}}=0
$$

Moreover,

$$
E_{t}^{L}<0 \text { and } E_{t}^{K}>0
$$

According to the first result of Lemma 3, a small increase in $q_{t}^{A}$, evaluated at the equilibrium, increases $V_{t}$, whereas such an increase in $q_{t}^{B}$ leaves $V_{t}$ unchanged. The reason for this asymmetry is the contemporaneous knowledge externality associated with labor-saving investments. Void of such an externality, the competitive economy chooses the level $q_{t}^{B}$ that maximizes income. Accordingly, $\partial V_{t} / \partial q_{t}^{B}=$ 
$0 .{ }^{18}$ The positive knowledge externality associated with labor-saving investments leads to under-investment in equilibrium. Therefore, having more of $q_{t}^{A}$ increases $V_{t}$ at the margin. ${ }^{19}$

The second result of Lemma 3 uses the reasoning above to conclude from (5.6) that $E_{t}^{L}<0$ and $E_{t}^{K}>0$. Hence, both a decline in the labor force and an increase in the capital stock induce more labor-saving technical change that increases income.

The following proposition compares the evolution of aggregate and per-capita income between period $t$ and $t+1$ in the economies of Proposition 2. I denote the equilibrium income obtained under $\lambda$ or $v$ by $V_{t+1}=V\left(b_{t+1} K_{t+1}, a_{t+1} L_{t+1}\right)$ and the one obtained under $\lambda^{\prime}$ or $v^{\prime}$ by $V_{t+1}^{\prime}=V\left(b_{t+1}^{\prime} K_{t+1}^{\prime}, a_{t+1}^{\prime} L_{t+1}^{\prime}\right)$.

Proposition 3 Consider two economies with identical initial conditions $\left(K_{t}, L_{t}, A_{t-1}, B_{t-1}\right)$ at some period $t \geq 1$.

1. If the cohorts $t$ of these economies have different fertility rates, $\lambda>\lambda^{\prime}$, that are not too far apart, then

$$
\begin{gathered}
V_{t+1}^{\prime} \lesseqgtr V_{t+1} \Leftrightarrow \\
{\left[\left(R_{t+1}+E_{t+1}^{K}\right)\left(\frac{K_{t+1}}{L_{t+1}}\right)\left(\frac{-\varepsilon}{1-\varepsilon}\right)+\left(w_{t+1}+E_{t+1}^{L}\right)\right]\left(\lambda^{\prime}-\lambda\right) \lesseqgtr 0,}
\end{gathered}
$$

\footnotetext{
${ }^{18}$ See Irmen (2012) a for a detailed discussion. Related results appear in the competitive economies studied in Zeira (1998) and Acemoglu (2010).

${ }^{19}$ To see by how much, a productivity effect and an investment effect of opposite sign must be considered. There is a productivity effect since labor becomes more productive. Therefore, more tasks must be performed to satisfy the full employment condition (4.2), $n_{t}=A_{t-1}(1-\delta)(1+$ $\left.\left(1+\eta^{A}\right) q_{t}^{A}\right) L_{t}$. This gives $A_{t-1}(1-\delta)\left(1+\eta^{A}\right) L_{t}$ additional tasks. As each of these contributes $w_{t} l_{t}=w_{t} / a_{t}$ to income, the productivity effect accounts for $A_{t-1}(1-\delta)\left(1+\eta^{A}\right) L_{t} w_{t} / a_{t}$ additional income.

The investment effect reduces income since for each task already performed, the investment outlays increase by $i^{\prime}\left(q_{t}^{A}\right)$. Therefore, total additional investment outlays increase by $A_{t-1}(1-\delta)\left(1+\left(1+\eta^{A}\right) q_{t}^{A}\right) L_{t} i^{\prime}\left(q_{t}^{A}\right)$. Since firms minimize costs, I have from (3.9) that $(1+$ $\left.\left(1+\eta^{A}\right) q_{t}^{A}\right) i^{\prime}\left(q_{t}^{A}\right)=w_{t} / a_{t}$. Hence, investment outlays increase by $A_{t-1}(1-\delta) L_{t} w_{t} / a_{t}$.

The difference between both effects is $\eta^{A} A_{t-1}(1-\delta) L_{t} w_{t} / a_{t}$. With (3.16) this is equal to $\eta^{A}$ times economy's wage bill discounted by the growth factor of labor productivity, i.e., $\eta^{A} w_{t} L_{t} /\left(1+\left(1+\eta^{A}\right) q_{t}^{A}\right)$.
} 
and

$$
\begin{gathered}
v_{t+1}^{\prime} \lesseqgtr v_{t+1} \Leftrightarrow \\
{\left[\left(R_{t+1}+E_{t+1}^{K}\right)\left(\frac{K_{t+1}}{L_{t+1}}\right)\left(\frac{-\varepsilon}{1-\varepsilon}\right)+\left(w_{t+1}+E_{t+1}^{L}-v_{t+1}\right)\right]\left(\lambda^{\prime}-\lambda\right) \lesseqgtr 0,}
\end{gathered}
$$

where $\varepsilon$ is evaluated at $\kappa_{t+1}$.

2. If the cohorts $t$ of these economies have different survival probabilities between $t$ and $t+1, v^{\prime}>v$, that are not too far apart, then

$$
\begin{gathered}
V_{t+1}^{\prime}>V_{t+1} \text { since } \\
\left(R_{t+1}+E_{t+1}^{K}\right)\left(\frac{s_{v}\left(R_{t+1}, v\right) w_{t} L_{t}}{1-\varepsilon}\right)\left(v^{\prime}-v\right)>0,
\end{gathered}
$$

and

$$
\begin{gathered}
v_{t+1}^{\prime} \gtreqless v_{t+1} \Leftrightarrow \\
{\left[\left(R_{t+1}+E_{t+1}^{K}\right)\left(\frac{s_{v}\left(R_{t+1}, v\right) w_{t}}{1-\varepsilon}\right)-v_{t+1}\right]\left(v^{\prime}-v\right) \gtreqless 0,}
\end{gathered}
$$

where $\varepsilon$ is evaluated at $\kappa_{t+1}$.

Roughly speaking, the results of (5.9) - (5.12) reveal that the effect of population aging on the growth rate of aggregate and per-capita income hinges on the sign and the strength of the induced effects on technical change and on the response of savings. Only the effect of a higher survival probability on income growth has an unequivocally positive sign. This is so since a higher survival probability induces more savings. The concomitant (total) effect of a higher capital stock on income is positive and given by

$$
\frac{d V_{t+1}}{d K_{t+1}}=\frac{\partial V_{t+1}}{\partial K_{t+1}}+E_{t+1}^{K}=R_{t+1}+E_{t+1}^{K}>0 .
$$


It reflects a direct effect, $\partial V_{t+1} / \partial K_{t+1}=R_{t+1}>0$, and an indirect effect, $E_{t+1}^{K}>0$, inducing more labor-saving technical change. ${ }^{20}$ As shown in (5.12), the effect of life-expectancy on per-capita income is not necessarily positive since more survivors increase the population in $t+1$.

The effect of a decline in fertility is more involved since it triggers both a decline in the work force and an adjustment of the capital stock. The former channel leads to a smaller workforce in the $\lambda^{\prime}$-economy. This reduces income since the (total) effect of the workforce on income is positive, i. e.,

$$
\frac{d V_{t+1}}{d L_{t+1}}=\frac{\partial V_{t+1}}{\partial L_{t+1}}+E_{t+1}^{L}=w_{t+1}+E_{t+1}^{L}>0,
$$

even though $E_{t+1}^{L}<0 .{ }^{21}$ Hence, the direct effect, $\partial V_{t+1} / \partial L_{t+1}=w_{t+1}>0$, dominates the indirect effect that induces less labor-saving technical change. Accordingly, for $V_{t+1}^{\prime}<V_{t+1}$, it is sufficient to have $\varepsilon \leq 0$, i. e., the savings rate must not decline in response to a higher real rental rate of capital. Given that the latter is the most likely response of the savings rate to changes in the rental rate of capital, the prediction is that the $\lambda^{\prime}$-economy has a lower growth rate of income. However, this does not imply that a lower fertility rate slows down growth of per-capita income. Condition (5.10) highlights that $v_{t+1}^{\prime}>v_{t+1}$ is easier to satisfy since the population at $t+1$ is smaller under $\lambda^{\prime}$. For instance, if the response of savings to the real rental rate is negligible a decline in fertility increases the growth rate of per-capita income in the short run if $w_{t+1}+E_{t+1}^{L}-v_{t+1}<0$.

\subsection{Population Aging and Economic Growth in the Long-Run}

The focus here is on the effects of population aging on economic growth in the steady state of the dynamical system of Proposition 1 . As will become clear below, to derive interpretable results at a high level of generality, I need to impose more

\footnotetext{
${ }^{20}$ From (5.5), the direct effect of $K_{t+1}$ on $V_{t+1}$ is $\partial V_{t+1} / \partial K_{t+1}=b_{t+1}\left[F_{1}(\cdot)-i\left(q_{t+1}^{B}\right)\right]$. It has an interpretation as the marginal contribution of capital to income given $q_{t+1}^{A}$ and $q_{t+1}^{B}$. From (3.12), it is indeed equal to $R_{t+1}$.

${ }^{21}$ To see this, note that $\partial V_{t+1} / \partial L_{t+1}=a_{t+1}\left[F_{2}(\cdot)-i\left(q_{t+1}^{A}\right)\right]$ is the marginal contribution of labor to income. From (3.11), the latter is equal to $w_{t+1}$. Then, using Lemma 1 and Lemma 2, one readily verifies that the sign of $\partial V_{t+1} / \partial L_{t+1}$ follows since $w_{t+1}\left[1-\left(\eta^{A} /\left(1+\eta^{A}\right)\right)\left(\varepsilon_{\kappa}^{A}\left(\kappa_{t+1}, \eta^{A}\right) \cdot \varepsilon^{\mathcal{K}}\left(\kappa_{t+1}\right)\right)\right]>0$. Hence, the induced effect of $L_{t+1}$ weakens the partial effect, however, without dominating it.
} 
structure. Therefore, I strengthen condition (4.11) and henceforth assume that ${ }^{22}$

$$
\varepsilon\left(\kappa_{t+1}\right) \leq 0 \text { for all } \kappa_{t+1}>0 .
$$

This is equivalent to the stipulation that individuals do not decrease their savings in response to an increase in the real rental rate of capital, i. e., $s_{R}\left(R_{t+1}, v\right) \geq 0$ or $\varepsilon_{R}^{s}\left(\kappa_{t}\right) \geq 0$.

Moreover, to study the local stability properties of a steady state let me denote the two sets $\left\{\left(B_{t}, \kappa_{t}\right) \mid \kappa_{t+1}-\kappa_{t}=0\right\}$ and $\left\{\left(B_{t}, \kappa_{t}\right) \mid B_{t+1}-B_{t}=0\right\}$ by $\Delta \kappa_{t}=0$ and $\Delta B_{t}=0$, respectively. I also assume that the evolution of $\kappa_{t}$ is stable, at least in the vicinity of $\Delta \kappa_{t}=0$. This assumption allows for a meaningful comparison of steady states in a world with and without capital-saving technical change (see, e. g., Section 6.1).

Define a steady state as a trajectory along which all variables grow at a constant rate. I deduce from (4.10) that a trajectory with $B_{t+1} / B_{t}-1=$ const. requires $\kappa_{t}=\kappa_{t+1}=\kappa^{*}$. Moreover, according to (4.9), the latter needs $B_{t+1}=B_{t}=B^{*}$. Hence, a steady state is a solution to

$$
\begin{aligned}
\frac{s\left(R\left(\kappa^{*}, B^{*}\right), v\right)}{1+\lambda} \tilde{w}\left(\kappa^{*}\right) & =\frac{\kappa^{*}}{B^{*}}(1-\delta)\left(1+\left(1+\eta^{A}\right) g^{A}\left(\kappa^{*}, \eta^{A}\right)\right), \\
g^{B}\left(\kappa^{*}\right) & =\frac{\delta}{1-\delta} .
\end{aligned}
$$

\section{Proposition 4 (Steady State)}

1. There is a unique steady state involving $\kappa^{*} \in(0, \infty)$ and $B^{*} \in(0, \infty)$ if and only if

$$
\lim _{\kappa \rightarrow 0} f^{\prime}(\kappa)>\frac{i^{\prime}\left(\frac{\delta}{1-\delta}\right)}{1-\delta}+i\left(\frac{\delta}{1-\delta}\right)>\lim _{\kappa \rightarrow \infty} f^{\prime}(\kappa) .
$$

2. The steady-state growth rate of the economy is

$$
g^{*} \equiv \frac{A_{t+1}}{A_{t}}=(1-\delta)\left(1+\left(1+\eta^{A}\right) g^{A}\left(\kappa^{*}, \eta^{A}\right)\right)-1 .
$$

\footnotetext{
${ }^{22}$ Without this assumption, neither the existence nor the uniqueness of a steady state may be established. Indeed, one readily verifies that, given $\kappa^{*}$, equation (5.15) below may determine none or several values $B^{*}>0$ if $s_{R}\left(R_{t+1}, v\right)$ was allowed to be negative.
} 
Moreover, along a steady-state path, I have
a) $\frac{v_{t+1}}{v_{t}}=\frac{a_{t+1}}{a_{t}}=\frac{w_{t+1}}{w_{t}}=\frac{c_{t+1}^{y}}{c_{t}^{y}}=\frac{c_{t+1}^{o}}{c_{t}^{o}}=\frac{s_{t+1}}{s_{t}}=1+g^{*}$ ，
b) $\frac{V_{t+1}}{V_{t}}=\frac{Y_{t+1}}{Y_{t}}=\frac{K_{t+1}}{K_{t}}=\frac{n_{t+1}}{n_{t}}=\frac{m_{t+1}}{m_{t}}=\left(1+g^{*}\right)(1+\lambda)$,
c) $\quad B_{t}=b_{t}=B^{*}, \quad R^{*}=B^{*} \frac{i^{\prime}\left(\frac{\delta}{1-\delta}\right)}{1-\delta}, \quad k_{t}=k^{*}=\frac{1}{B^{*}}, \quad \frac{l_{t+1}}{l_{t}}=\frac{1}{1+g^{*}}$,

3. If the set $\Delta \kappa_{t}=0$ is stable in the vicinity of $\left(\kappa^{*}, B^{*}\right)$, then the steady state is either a stable node, a focus, or a clockwise spiral sink. A typical phase diagram looks like the one of Figure 5.1.

Proposition 4 states several important properties of a steady state. According to Statement 1 , a finite and unique steady state exists if and only if, at the equilibrium allocation, a small (large) stock of efficient capital has a sufficiently high (low) marginal value product. ${ }^{23}$ More precisely, condition (5.17) assures that a choice $q^{B}=\delta /(1-\delta)$ is profit-maximizing for some $\kappa \in(0, \infty)$. Intuitively, such a choice implies a total cost of the marginal task $m_{t}$ equal to $i^{\prime}(\delta /(1-\delta)) /(1-$ $\delta)+i(\delta /(1-\delta))$. Hence, for $m<m_{t}$ the marginal value product must exceed, for $m>m_{t}$ it must fall short of these costs. This is precisely what condition (5.17) assures. Notice that a value $\kappa^{*} \in(0, \infty)$ would always exist if I had imposed the usual Inada conditions on $F$.

Statement 2 of Proposition 4 gives the steady-state evolution of all admissible variables. The steady-state growth rate of the economy, $g^{*}$, is given by the growth rate of the stock of labor-saving technological knowledge. Per-capita income, labor productivity, the real wage, individual consumption and individual savings grow at this rate.

A central conclusion of my analysis is that $g^{*}$ is independent of population aging. ${ }^{24}$ The reason for this finding is the following. The steady state requires profit-

\footnotetext{
${ }^{23}$ The role of diminishing returns for the existence of a steady state is similar to the neoclassical growth model of Solow (1956) and Swan (1956). However, here the intuition is quite different.

${ }^{24}$ What then explains different steady-state growth rates in the present model? A comprehensive answer is beyond the scope of this paper. Observe, however, that a higher $\eta^{A}$ unequivocally increases $g^{*}$ since the (positive) direct effect dominates the (negative) indirect effect through $g^{A}\left(\kappa^{*}, \eta^{A}\right)$. Moreover, if I replace the production function (3.4) by $Y_{t}=\Gamma F\left(m_{t}, n_{t}\right)$, where $\Gamma>0$ reflects cross-country differences in geography, technical or social infrastructure, then $g^{*}$ is strictly increasing in $\Gamma$.
} 
Figure 5.1: The Phase-Diagram of the Locally Stable Steady State $\left(\kappa^{*}, B^{*}\right)$.

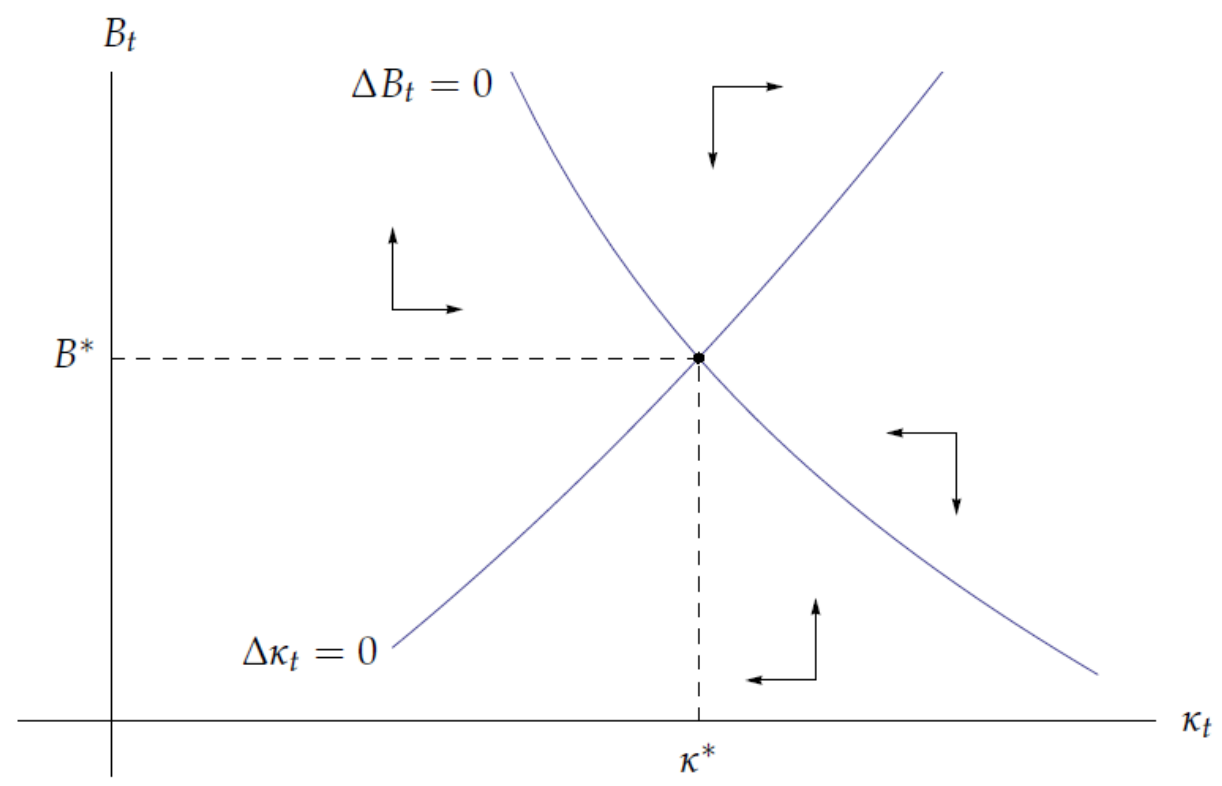

maximizing investments in capital-saving technical change to generate capitalsaving technical progress that just offsets the depreciation of capital-saving technological knowledge. ${ }^{25}$ The role of the steady-state efficient capital intensity is then to induce that sort of investment behavior. This explains why condition (5.16) determines $\kappa^{*}$. Moreover, both $g^{B}(\cdot)$ and $g^{A}(\cdot)$ reflect only the characteristics of the production side of the economy. Therefore, $\kappa^{*}$ and, hence, $g^{*}$ are independent of population aging.

The growth rate of aggregate variables such as $V_{t}, Y_{t}$, or $K_{t}$ is approximately equal to $g^{*}+\lambda$. Hence, an older economy experiences slower growth of economy-wide variables. The rental rate of capital is constant. Moreover, one readily verifies that the steady-state functional income distribution is also constant and independent of population aging. With these results at hand, it is straightforward to see that the steady state is consistent with Kaldor's facts (Kaldor (1961)) as long as $g^{*}>0$.

According to Statement 3 of Proposition 4, the steady state is locally stable. Figure 5.1 shows the phase diagram with both loci, $\Delta \kappa_{t}=0$ and $\Delta B_{t}=0$, being stable. Hence, a one-time increase in the OADR due to a variation in $\lambda$ or $v$ leaves the steady state of the economy unaffected. The convergence to the steady state may either be monotonic or oscillatory depending on the extent to which the OADR

\footnotetext{
${ }^{25}$ Hence, in steady state there is no growth of capital-saving technological knowledge. See Irmen (2013) for a discussion of the conceptual underpinning of this result.
} 
affects the eigenvalues of the dynamical system. The following proposition gives the steady-state effects of a permanent increase in the OADR.

Proposition 5 Consider two economies with identical initial conditions $\left(K_{1}, L_{1}, A_{0}, B_{0}\right)$.

1. If these economies differ only with respect to their fertility rates, such that $\lambda>\lambda^{\prime}$ for all $t=1,2, \ldots, \infty$, then, their steady states satisfy $\kappa^{*}=\kappa^{* \prime}, B^{*}>B^{* \prime}$, and $R^{*}>R^{* \prime}$.

2. If these economies differ only with respect to their survival probability, such that $v^{\prime}>v$ for all $t=1,2, \ldots, \infty$, then their steady states satisfy $\kappa^{*}=\kappa^{* \prime}, B^{*}>B^{* \prime}$, and $R^{*}>R^{* \prime}$.

While population aging does not affect the steady-state growth rate, it implies adjustment in steady-state levels. According to Proposition 5, the 'older' economy has a lower steady-state level of capital-saving technological knowledge and, therefore, a lower steady-state rental rate of capital. Intuitively, both a decline in the fertility rate and/or a higher survival probability increase, ceteris paribus, $s\left(R\left(\kappa^{*}, B^{*}\right), v\right) /(1+\lambda)$. Since $\kappa^{*}$ is fixed, the necessary adjustment in (5.15) occurs through a decline in $B^{*}$ and the concurrent fall of the steady-state real rental rate of capital.

These findings may be sharpened if the savings rate does not respond to changes in the real rental rate of capital. ${ }^{26}$

Proposition 6 Reconsider the two economies of Proposition 5. Assume $s_{R}\left(R_{t+1}, v\right)=$ 0 , and let the convergence to the respective steady states be monotonous.

1. If the two economies differ only with respect to their survival probability, such that $v^{\prime}>v$ for all $t=1,2, \ldots, \infty$, then

$$
\lim _{t \rightarrow \infty} \frac{V_{t}^{\prime}}{V_{t}}>1
$$

\footnotetext{
${ }^{26}$ Bloom, Canning, and Graham (2003) provide empirical support for the view that the effect of the interest rate on the savings rate is small. These authors also find a significant positive effect of longevity on the savings rate.
} 
2. Independent of the source of aging, it holds that

$$
\lim _{t \rightarrow \infty} \frac{V_{t}^{\prime} / L_{t}^{\prime}}{V_{t} / L_{t}}=\lim _{t \rightarrow \infty} \frac{w_{t}^{\prime}}{w_{t}}>1
$$

Hence, if longevity is the source of aging, then the older economy will have a greater income in the long run than the younger one. The reason is to be found in the evolution of the efficient capital intensity along the transition. While both economies start at the same level, $\kappa_{1}^{\prime}=\kappa_{1}$, and converge to the same level $\kappa^{* \prime}=\kappa^{*}$ it holds that $\kappa_{t}^{\prime}>\kappa_{t}$ for all $t=2,3, \ldots, \tau$, where $\tau<\infty$. Intuitively, from the analysis of the short-run effects it is clear that population aging increases the capitallabor ratio in $t=2$. This induces technical change such that $A_{2}^{\prime}>A_{2}$. Moreover, $\kappa_{2}^{\prime}>\kappa_{2}$. Since $s\left(v^{\prime}\right) \geq s(v)$ and/or $\lambda^{\prime} \leq \lambda$, the dynamical system maintains the tendency of a greater efficient capital intensity in the older economy over any finite time span. Accordingly, for any period $\tau$ the level of labor-saving technological knowledge satisfies $A_{\tau}^{\prime}>A_{\tau}$. Since steady state income is proportionate to efficient labor, $A_{t} L_{t}$, Claim 1 reflects the effect of a permanently higher survival probability on the incentives to engage labor-saving technical change throughout the transition. ${ }^{27}$

This intuition extends to Claim 2 of Proposition 6 which states that in steady state the older economy has both a greater labor productivity as well as a higher real wage. The ratio of both variables hinges only on $A_{t}^{\prime} / A_{t}$.

\section{Discussion and Extensions}

\subsection{The Role of Capital-Saving Technical Change}

To further explore the role of capital-saving technical change, it proves useful to establish the effect of population aging in an economy without it. To accomplish this, recall that the dynamical system of Proposition 1 nests the case of an economy with endogenous labor-saving technical change only. It obtains if I set $q_{t}^{B}(m)=0$ and fix $b_{t}=B_{t}=B>0$ for all $t$. Then, given $\left(K_{1}, L_{1}, A_{0}\right)>0$ as

\footnotetext{
${ }^{27}$ Observe that in steady state $V_{t}^{\prime} / V_{t}=A_{t}^{\prime} L_{t}^{\prime} /\left(A_{t} L_{t}\right)$. Hence, if aging was due to a lower fertility rate then the overall effect on steady-state income depends on the strength of the two opposing effects, namely $A_{t}^{\prime} / A_{t}>1$ and $L_{t}^{\prime} / L_{t}<1$. A similar conflict arises for the comparison of steady-state income per-capita.
} 
initial conditions, $B=1$, and (4.11), the dynamical system determines a unique equilibrium sequence $\left\{\kappa_{t}\right\}_{t=1}^{\infty}$ that satisfies

$$
\frac{s\left(R\left(\kappa_{t+1}\right), v\right)}{1+\lambda} \tilde{w}\left(\kappa_{t}\right)=\kappa_{t+1}(1-\delta)\left(1+\left(1+\eta^{A}\right) g^{A}\left(\kappa_{t+1}, \eta^{A}\right)\right),
$$

with $\kappa_{1}$ given by

$$
\kappa_{1}=\frac{K_{1}}{A_{0}(1-\delta)\left(1+\left(1+\eta^{A}\right) g^{A}\left(\kappa_{1}, \eta^{A}\right)\right) L_{1}}>0 .
$$

Does this economy respond to population aging in the same way as the one with capital-saving technical change? To see that the answer is no, consider the phase diagram of Figure 6.1. Suppose the economy starts in the steady state $\left(\kappa^{*}, B^{*}\right)$ before it experiences a one-time and permanent decline in $\lambda$ or increase in $v$.

In the economy with capital- and labor-saving technical change, this shock shifts the loci $\Delta \kappa_{t}=0$ and the $\Delta B_{t}=0$ downwards to intersect at $\left(\kappa^{* \prime}, B^{* \prime}\right)$. However, the economy without capital-saving technical change converges to the new steady state at $\kappa_{A}^{*}$ since the $\Delta \kappa_{t}=0$ - locus is stable and $B_{t}=B^{*}$ remains constant. Intuitively, along the transition there is continuous capital deepening inducing more and more labor-saving technical change. As a consequence, population aging is associated with an increase in the steady-state growth rate. ${ }^{28}$ However, if capital-saving technical change is possible, $\left(\kappa_{A}^{*}, B^{*}\right)$ cannot be a steady state: to the right of $\kappa^{*}$, the growth rate of $B_{t}$ is strictly negative. Following the initial shock the economy lands on a trajectory with $\kappa_{t}>\kappa^{*}$ and $B_{t}<B^{*}$ and, as shown in Figure 6.1, may converge to the new steady state $\left(\kappa^{*}, B^{* \prime}\right)$.

To sum up, the possibility of endogenous capital-saving technical change prevents population aging from having growth effects in the long run. In the vicinity of the steady state, an economy may then get older without affecting its trend growth rate, an evolution suggested by the empirical evidence presented in the Introduction.

\subsection{Capital-Saving Investments with Contemporaneous Knowl- edge Spill-Overs}

Thus far, the external contemporaneous knowledge spill-overs are confined to labor-saving investments. Authors like Frankel (1962) or Romer (1986) advocate

\footnotetext{
${ }^{28}$ Mutatis mutandis, these two forces are behind the steady-state analysis that appears, e. g., in Heer and Irmen (2009). A similar mechanism drives the results of population aging on the steadystate growth rate in Futagami and Nakajima (2001). The AK-model in Li, Zhang, and Zhang (2007) exhibits a jump that corresponds to a shift from $\left(\kappa^{*}, B^{*}\right)$ to $\left(\kappa_{A}^{*}, B^{*}\right)$ without a transition period.
} 
Figure 6.1: Comparative Statics and Dynamics of a One-Time and Permanent Decline (Increase) in the Growth Rate of the Labor Force (Survival Probability). The Case of a Stable Node.

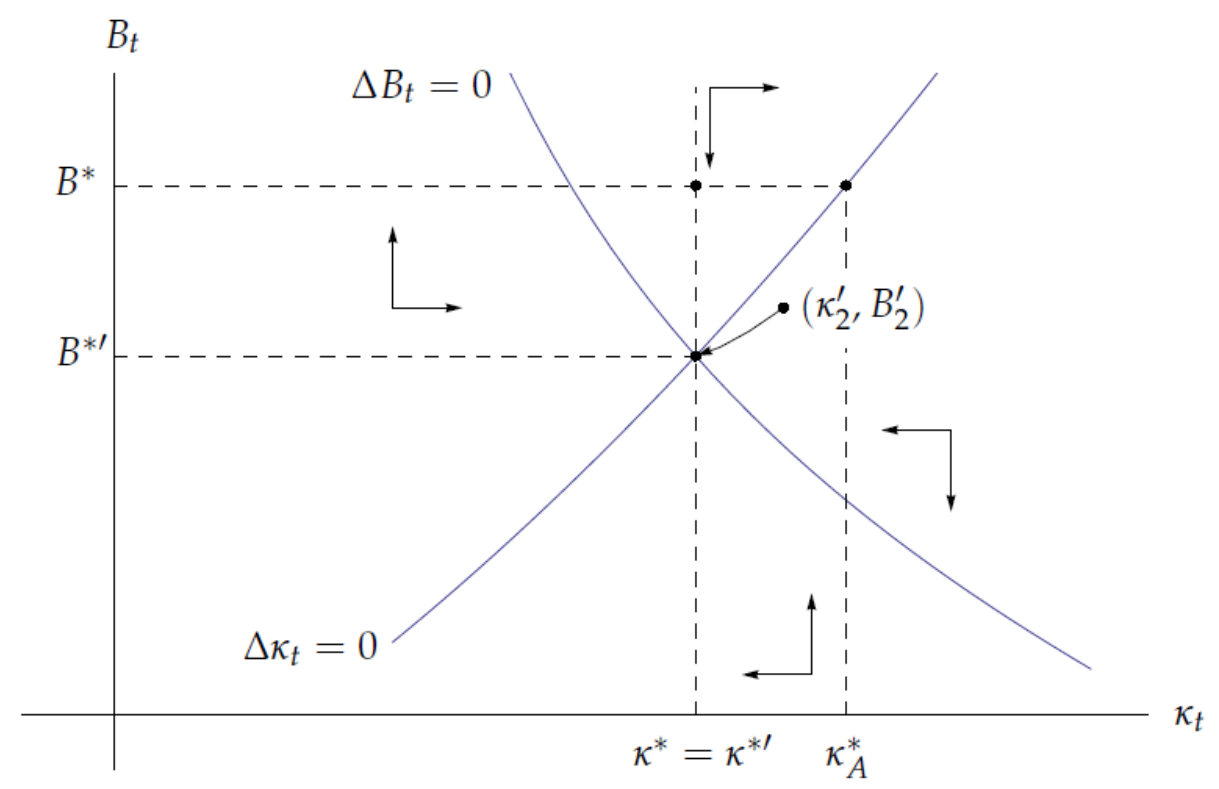

the presence of such spill-overs in the context of capital investments. One way to capture this is to replace $b_{t}(m)$ of (3.6) by

$$
\begin{aligned}
b_{t}(m) & =B_{t-1}(1-\delta)\left(1+q_{t}^{B}(m)+\eta^{B} e_{t}^{B}\right), \\
e_{t}^{B} & \equiv \frac{1}{m_{t}} \int_{0}^{m_{t}} q_{t}^{B}(m) d m,
\end{aligned}
$$

where $e_{t}^{B}$ is the external knowledge spill-over and $\eta^{B} \in \mathbb{R}_{+}$measures its strength.

The incorporation of these spill-overs requires some modifications, however, the main results of the analysis contained in Sections 3 - 5 remain valid. The reasoning that leads to Lemma 1 gives now rise to the map $g^{B}: \mathbb{R}_{++} \rightarrow \mathbb{R}_{++}$, where $q_{t}^{B}=g^{B}\left(\kappa_{t}, \eta^{B}\right)$ with $g_{\eta^{B}}^{B}\left(\kappa_{t}, \eta^{B}\right)<0$. Proposition 2 for the short run as well as all qualitative findings for the long-run remain valid. The most striking new aspect concerns the role of population aging for the evolution of income. Due to the new external knowledge spill-over I have for the same reasons that explain Lemma 3

$$
\frac{\partial V_{t}}{\partial q_{t}^{B}}=\frac{\eta^{B} R_{t} K_{t}}{1+\left(1+\eta^{B}\right) q_{t}^{B}}>0
$$

The consequence is that the induced effects that appear in both lines of (5.6) are now of opposite sign. Hence, $E_{t}^{L}$ and $E_{t}^{K}$ can no longer be signed. However, the 
signs for $d V_{t+1} / d K_{t+1}$ and $d V_{t+1} / d L_{t+1}$ established in (5.13) and (5.14) remain valid, i.e., the direct effects of a change in capital or labor on income dominate the induced effects. ${ }^{29}$ As a result, the qualitative results of Proposition 3 remain also true.

\subsection{Changing Demographic Features}

Three Generations Following, e. g., Bommier and Lee (2003), one may argue that a representation of economic life by three periods, childhood, adulthood, and old age, is called for to study the implications of population aging. To incorporate this consider three generations alive at each period $t \geq 1$, i.e., $v L_{t-1}$ retired old, $L_{t}$ working adults, and $L_{t+1}$ children. At the beginning of period $t$, each working adult gives birth to $\left(1+\lambda_{t+1}\right)$ offspring and maximizes his expected lifetime utility (3.2) having the offspring consumption included in $c_{t}^{y} \cdot{ }^{30}$

However, for two reasons the relevance of this extension is rather limited in the present context. First, for the short-run effects the crucial link is between fertility of adults at $t$ and the supply of labor at $t+1$. Adding a period of childhood does not affect this link. Therefore, the consequences of a decline in fertility stated in Proposition 2 and Proposition 3 remain valid. To the extent that fewer children reduce total population, an increase in per-capita income becomes more likely if fertility declines in two successive periods, i. e., condition (5.10) will be easier to satisfy for $v_{t+1}^{\prime}>v_{t+1}$. Second, the steady-state growth rate is independent of the economy's demographic structure. Hence, in the long run, the amount of periods an individual is supposed to live through does not affect the growth rate of the economy.

Underestimation of Survival Rates Perfect foresight includes the assumption that young individuals correctly foresee their survival rates. This seems unrealistic, especially in times where this rate considerably increases between genera-

\footnotetext{
${ }^{29}$ To see this formally, denote $E_{t}^{L}$ and $E_{t}^{K}$ of (5.6) by $E_{t}^{L}\left(\eta^{A}, \eta^{B}\right)$ and $E_{t}^{K}\left(\eta^{A}, \eta^{B}\right)$, respectively. Then, (6.2) implies $E_{t}^{L}\left(\eta^{A}, \eta^{B}\right)>E_{t}^{L}\left(\eta^{A}, 0\right)$. Hence, $w_{t}+E_{t}^{L}\left(\eta^{A}, \eta^{B}\right)>0$. Similarly, $E_{t}^{K}\left(\eta^{A}, \eta^{B}\right)>E_{t}^{K}\left(0, \eta^{B}\right)$. Therefore, the reasoning that leads to the conclusion that $\partial V_{t+1} / \partial L_{t+1}>0$ in (5.14) applied to $E_{t}^{K}\left(0, \eta^{B}\right)$ reveals that $R_{t}+E_{t}^{K}\left(\eta^{A}, \eta^{B}\right)>0$.

${ }^{30}$ This setup has been studied by, e. g., Zhang, Zhang, and Lee (2001). Here, the total dependency ratio may be a more appropriate indicator of economic dependency. It is equal to the sum of the old-age dependency ratio and the child dependency ratio, i. e., $\left(v L_{t-1}+L_{t+1}\right) / L_{t}=$ $v /\left(1+\lambda_{t}\right)+\left(1+\lambda_{t+1}\right)$.
} 
tions. ${ }^{31}$ One crude way to account for this is to allow for myopic foresight where the expected survival rate of cohort $t$ is $v_{t-1}$, i. e., the known survival rate of their parents. Then, an actual increase in the survival rate of cohort $t$ has no effects on their savings and the effect of changes in $v$ on $K_{t+1} / L_{t+1}$ derived in (5.4) vanishes. As a consequence, the impact of an increase in $v$ stated in Proposition 2 is just postponed by one period. The same is true for Proposition 3: the savings channel is mute between $t$ and $t+1$ so that $V_{t+1}^{\prime}=V_{t+1}$ in (5.11) and $v_{t+1}^{\prime}<v_{t+1}$ in (5.12). By definition, consecutive survival rates must be the same in steady state. Therefore, underestimation as introduced here leaves the steady state and its properties, i. e., Proposition 4, unaffected.

\subsection{Endogenous Labor Supply}

The labor supply of an individual may depend positively on the expected survival probability if people want to earn and save more expecting a longer period of retirement. To include this feature let $\tau_{t}=\tau(v)$ denote the fraction of an individual's time endowment that she supplies to the labor market at $t$. Here, ${ }^{32}$

$$
\tau_{t}=\tau(v), \quad \tau:[0,1] \rightarrow[0,1] \quad \text { with } \quad \tau^{\prime}(v)>0 .
$$

Accounting for this in (4.5) reveals that Lemma 2 must be extended since $\kappa_{t}=$ $\kappa(\cdot, v)$ with $\kappa_{v}<0$. Hence, a higher survival probability reduces the equilibrium task intensity since it increases the supply of labor. Then (5.2) becomes

$$
\frac{s\left(R\left(\kappa\left(\frac{B_{t} K_{t+1}}{A_{t} L_{t+1}}, v\right), B_{t}\right), v\right)}{1+\lambda} w_{t}=\frac{K_{t+1}}{L_{t+1} \tau(v)} .
$$

Moreover, as long as $s_{R} \geq 0$, it holds that $\partial\left(K_{t+1} / L_{t+1}\right) / \partial v>0$ so that the qualitative results of Proposition 2 remain valid.

Proposition 3 must be modified since now $v$ induces technical change that affects aggregate income. To account for this use the same steps that lead to (5.6) and

\footnotetext{
${ }^{31}$ See, e. g., Groneck, Ludwig, and Zimper (2011) for a discussion of behavioral biases in individual forecast errors of survival rates and their explanations.

${ }^{32}$ The function $\tau(v)$ may result as the optimal choice for a lifetime utility function

$$
U_{t}=\frac{\left[c_{t}^{y}\left(1-\tau_{t}\right)^{\theta}\right]^{1-\eta}}{1-\eta}+v \frac{\left(c_{t+1}^{o}\right)^{1-\eta}}{1-\eta},
$$

with $\theta \geq 0$ and $\eta>\theta /(1+\theta)$.
} 
obtain

$$
E_{t}^{v}=\left[\frac{\partial V_{t}}{\partial q_{t}^{A}} g_{\kappa}^{A}\left(\kappa_{t}, \eta^{A}\right)+\frac{\partial V_{t}}{\partial q_{t}^{B}} g_{\kappa}^{B}\left(\kappa_{t}\right)\right] \frac{\partial \kappa_{t}}{\partial \nu}<0,
$$

where the sign follows with Lemma 3. Intuitively, a higher life-expectancy means a larger labor supply and, therefore, less induced labor-saving technical change. Hence, output falls. This effect will pop up in the modified statements of (5.11) and (5.12) and weaken the prospect that population aging fosters aggregate and per-capita income growth. Again, this extension leaves the qualitative results on steady-state growth unaffected.

\subsection{Endogenous Fertility}

Thus far, population aging has two exogenous causes, a decline in fertility and an increase in life expectancy. This section touches on the question about the economic implications of population aging if fertility is endogenous. Clearly, a full-fledged discussion of this topic would call for a model involving an endogenous fertility choice. However, this is beyond the scope of the present paper. ${ }^{33}$ Instead, I stipulate a functional relationship where the fertility rate of generation $t$ depends in a negative way on its survival probability, i. e.,

$$
\lambda=\lambda(v), \quad \lambda:[0,1] \rightarrow(-1, \infty) \text { with } \lambda^{\prime}(v)<0 .
$$

This behavioral assumption is consistent with the recent experience of the industrialized world where fertility declines as life expectancy increases. ${ }^{34}$ As suggested, e.g., by Kirk (1996), p.379, it reflects the idea that mortality is a main cause of the fertility decline. Overall, this relationship may be driven by advances in the life and the medical sciences and the concomitant effects of better medical treatments and more reliable contraceptives.

With this specification the old-age dependency ratio at $t$ is

$$
O A D R_{t}=\frac{v}{1+\lambda(v)}, \quad \text { with } \quad \frac{d O A D R_{t}}{d v}=\frac{1}{1+\lambda(v)}\left(1-\frac{\lambda^{\prime}(v) v}{1+\lambda(v)}\right)>0,
$$

\footnotetext{
${ }^{33}$ See, e. g., Galor (2011) for a comprehensive discussion of the fertility-growth nexus.

${ }^{34}$ Soares (2005), Figure 4, shows the cross-sectional relationship between life-expectancy and fertility around 1960 and 1995 for post-demographic transition countries. This evidence suggests a stable functional relationship linking higher life expectancy to a lower fertility rate as stipulated by $\lambda(v)$ above. Soares also shows that such a relationship may emerge in theoretical models that account for a fully endogenous fertility choice (see also Cervellati and Sunde (2013)).
} 
Hence, the effect of increasing $v$ becomes more pronounced as the current young reduce their fertility in anticipation of a higher survival probability.

The most important modification of this feature concerns the clear-cut prediction of Proposition 3 that a rise in the survival probability increases aggregate income. Going through the steps that lead to (5.11), one now finds

$$
\begin{gathered}
V_{t+1}^{\prime} \gtreqless V_{t+1} \quad \text { if } \\
{\left[\left(R_{t+1}+E_{t+1}^{K}\right)\left(\frac{K_{t+1}}{1+\lambda(v)} \frac{-\varepsilon}{1-\varepsilon}\right)+\left(w_{t+1}+E_{t+1}^{L}\right)\right] \lambda^{\prime}(v)\left(v^{\prime}-v\right)} \\
+\left(R_{t+1}+E_{t+1}^{K}\right)\left(\frac{s_{v}\left(R_{t+1}, v\right) w_{t}}{1-\varepsilon}\right)\left(v^{\prime}-v\right) \gtreqless 0,
\end{gathered}
$$

The first line of (6.5) states the new effect on income that a rise in the survival probability induces through a decline in fertility. From the discussion of (5.9) the term in brackets is positive if $s_{R} \geq 0$. Then, as $\lambda^{\prime}(v)<0$ the induced effect is negative. This weakens the positive effect of an increase in life-expectancy on economic growth through an increase in savings identified in (5.11). Hence, the overall effect becomes indeterminate in general. Finally, observe that the steadystate growth rate of the economy with endogenous fertility is still given by $g^{*}$ of Proposition 4. This is so since fertility does not interfere with the way the production sector determines $\kappa^{*}$.

\section{Concluding Remarks}

This paper studies the role of population aging for economic growth. It claims that demographic change affects the investment behavior of firms with implications for technical progress and economic growth. A central result of the analysis is that the type of technical progress is crucial for the link between population aging and economic growth. To make this point, this paper extends the existing literature and allows for two types of endogenous technical progress, i. e., capitaland labor-saving technical change.

Capital-saving technical change is found to imply that the steady-state growth rate is independent of the economy's age structure. Hence, in the long run, economic growth is independent of demographic features. This finding is consistent with the recent experience of the US - economy. However, population 
aging affects economic growth along the transition since it accentuates the relative scarcity of labor with respect to capital. This leads to more labor- and less capital-saving technical change. Due to external contemporaneous knowledge spill-overs, this induced change in the direction of technical change is found to have first-order effects on the evolution income.

The present analysis suggests several routes for future research. They include the question about how population aging affects economic growth if the age structure of the labor force matters for the direction of technical change. Case studies like Nishimura, Minetaki, Shirai, and Kurokawa (2002) for Japan, Prskawetz, Kögel, Sanderson, and Scherbov (2007) for India, or the panel study of Feyrer (2007) suggest a role of population aging for economic growth beyond its effect on the scarcity of the entire labor force relative to capital.

Second, one may want to inquire into the scope for design of growth policies to meet the economic challenges of population aging. This will require an analysis of the welfare properties of the equilibrium. Due to the presence of contemporaneous and inter-temporal external effects the equilibrium will in general not be efficient. This leaves room for fiscal policy measures to improve the normative properties of the competitive equilibrium. However, the main insight of this paper suggests that the effects and the desirability of any growth policy will crucially depend on whether technical change is capital-saving in addition to being labor-saving. I leave these questions for future research. 


\section{Appendix: Proofs}

\subsection{Proof of Lemma 1}

Consider (3.9) - (3.12) at $q_{t}^{A}(n)=q_{t}^{A}=e_{t}^{A}$ and $q_{t}^{B}(m)=q_{t}^{B}$. Upon substitution of (3.9) in (3.11) and (3.10) in (3.12) I obtain

$$
\begin{aligned}
f\left(\kappa_{t}\right)-\kappa_{t} f^{\prime}\left(\kappa_{t}\right) & =\left(1+\left(1+\eta^{A}\right) q_{t}^{A}\right) i^{\prime}\left(q_{t}^{A}\right)+i\left(q_{t}^{A}\right), \\
f^{\prime}\left(\kappa_{t}\right) & =\left(1+q_{t}^{B}\right) i^{\prime}\left(q_{t}^{B}\right)+i\left(q_{t}^{B}\right) .
\end{aligned}
$$

Denote $\operatorname{RHS}(q, \eta)$ the right-hand side of both conditions with the understanding that $\eta=0$ in the second one. In view of the properties of the function $i$ given in (3.7), $R H S(q, \eta)$ is a mapping RHS : $\mathbb{R}_{+}^{2} \rightarrow \mathbb{R}_{+}$with $\lim _{q \rightarrow 0} \operatorname{RHS}(q, \eta)=0, \operatorname{RHS}_{q}(q, \eta)>0$ for $q>0, \lim _{q \rightarrow 0} \operatorname{RHS}_{q}(q, \eta)=$ $i^{\prime \prime}(q) \geq 0$, and $\lim _{q \rightarrow \infty} \operatorname{RHS}(q, \eta)=\infty$. Moreover, the properties of the function $f\left(\kappa_{t}\right)$ imply that the left-hand side of both conditions is strictly positive for $\kappa_{t}>0$. Hence, for each $\kappa_{t}>0$ there is a unique $q_{t}^{j}>0, j=A, B$, that satisfies the respective condition stated in (8.1). I denote these maps by $q_{t}^{A}=g^{A}\left(\kappa_{t}, \eta^{A}\right)$ and $q_{t}^{B}=g^{B}\left(\kappa_{t}\right)$, respectively.

An application of the implicit function theorem to (8.1) gives

$$
\frac{d q_{t}^{A}}{d \kappa_{t}} \equiv g_{\kappa}^{A}\left(\kappa_{t}, \eta^{A}\right)>0, \quad \frac{d q_{t}^{A}}{d \eta^{A}} \equiv g_{\eta^{A}}^{A}\left(\kappa_{t}, \eta^{A}\right)<0, \quad \text { and } \quad \frac{d q_{t}^{B}}{d \kappa_{t}} \equiv g_{\mathcal{\kappa}}^{B}\left(\kappa_{t}\right)<0 .
$$

The respective signs follow from the properties of the functions $f$ and $i$.

With $q_{t}^{A}=g^{A}\left(\kappa_{t}, \eta^{A}\right)$ and $q_{t}^{B}=g^{B}\left(\kappa_{t}\right)$, I may express $w_{t}$ and $R_{t}$ using the respective first-order condition of (3.9) and (3.10). Then,

$$
\begin{aligned}
& w_{t}=A_{t-1}(1-\delta)\left(1+\left(1+\eta^{A}\right) g^{A}\left(\kappa_{t}, \eta^{A}\right)\right)^{2} i^{\prime}\left(g^{A}\left(\kappa_{t}, \eta^{A}\right)\right) \equiv w\left(\kappa_{t}, A_{t-1}\right), \\
& R_{t}=B_{t-1}(1-\delta)\left(1+g^{B}\left(\kappa_{t}\right)\right)^{2} i^{\prime}\left(g^{B}\left(\kappa_{t}\right)\right) \equiv R\left(\kappa_{t}, B_{t-1}\right) .
\end{aligned}
$$

The properties stated in (3.14) are immediate. For further reference, notice that the sign of the partial derivatives $w_{\mathcal{K}}\left(\kappa_{t}, A_{t-1}\right)$ and $R_{\mathcal{K}}\left(\kappa_{t}, B_{t-1}\right)$ carry over to the respective factor prices in efficiency units, i. e., to $\tilde{w}\left(\kappa_{t}\right) \equiv w\left(\kappa_{t}, A_{t-1}\right) / a_{t}=\left(1+\left(1+\eta^{A}\right) g^{A}\left(\kappa_{t}\right)\right) i^{\prime}\left(g^{A}\left(\kappa_{t}\right)\right)$ and $\tilde{R}\left(\kappa_{t}\right) \equiv$ $R\left(\kappa_{t}, B_{t-1}\right) / b_{t}=\left(1+g^{B}\left(\kappa_{t}\right)\right) i^{\prime}\left(g^{B}\left(\kappa_{t}\right)\right)$.

\subsection{Proof of Lemma 2}

Equation (4.5) is a fixed-point problem with a unique solution $\kappa\left(B_{t-1} K_{t} / A_{t-1} L_{t}, \eta^{A}\right)>0$. To see this, write the right-hand side of (4.5) as RHS $\left(\kappa_{t}, B_{t-1} K_{t} / A_{t-1} L_{t}, \eta^{A}\right)$. Given the properties of $g^{A}\left(\kappa_{t}, \eta^{A}\right)$ and $g^{B}\left(\kappa_{t}\right)$ as stated in (3.13) and $B_{t-1} K_{t} / A_{t-1} L_{t}>0$, RHS $\left(\kappa_{t}, B_{t-1} K_{t} / A_{t-1} L_{t}, \eta^{A}\right)$ is a function which is continuous, strictly decreasing, and strictly positive for all $\kappa_{t}>0$. Hence, $\lim _{\kappa_{t} \rightarrow 0} R H S\left(\kappa_{t}, \cdot\right)>0$. Accordingly, there is a unique $\kappa>0$ such that $\kappa=R H S(\kappa, \cdot)$. Implicit differentiation of (4.5) delivers (4.7). 


\subsection{Proof of Proposition 1}

Given $\left(K_{t}, L_{t}, A_{t-1}, B_{t-1}\right)$, it is straightforward to establish that the variables $\kappa_{t}$ and $B_{t}$ are indeed state variables of the economy at $t$. To prove the existence of a unique equilibrium sequence $\left\{\kappa_{t}, B_{t}\right\}_{t=1}^{\infty}$ let me first derive equation (4.9). To do so solve (4.5) for $K_{t+1}$ and substitute the resulting expression into (4.8). Using $s_{t}=s\left(R\left(\kappa_{t+1}, B_{t}\right), v\right) w\left(\kappa_{t}\right)$ and $\tilde{w}\left(\kappa_{t}\right) \equiv w\left(\kappa_{t}\right) / a_{t}$ gives (4.9) after some straightforward manipulations. The difference equation (4.10) is from (3.16) where $q_{t}^{B}$ is replaced by $g^{B}\left(\kappa_{t}\right)$ in accordance with Lemma 1 . In the first period, $\kappa_{1}$ is pinned down by (4.5) for given initial values $\left(K_{1}, L_{1}, A_{0}, B_{0}\right)>0$. From Lemma 2 , there is a unique solution $\kappa_{1}>0$.

To prove the uniqueness of the sequence $\left\{\kappa_{t}, B_{t}\right\}_{t=1}^{\infty}$ it is useful to introduce

$$
\Psi\left(\kappa_{t}, B_{t-1}\right) \equiv \frac{1+\left(1+\eta^{A}\right) g^{A}\left(\kappa_{t}, \eta^{A}\right)}{1+g^{B}\left(\kappa_{t}\right)} \frac{\kappa_{t}(1+\lambda)}{s\left(R\left(\kappa_{t}, B_{t-1}\right), v\right)} .
$$

Then, (4.9) may be written as

$$
B_{t} \tilde{w}\left(\kappa_{t}\right)=\Psi\left(\kappa_{t+1}, B_{t}\right)
$$

From (8.2) the left-hand side of (8.4) is strictly positive for any $\left(\kappa_{t}, B_{t}\right) \in \mathbb{R}_{++}^{2}$. Hence, there is a unique value $\kappa_{t+1}>0$ that satisfies (8.4) if $\Psi\left(\kappa_{t+1}, B_{t}\right)$ is strictly positive, continuous, monotone in $\kappa_{t+1}$, and may take on all values in $\mathbb{R}_{++}^{2}$ as $\kappa_{t+1}$ varies.

To see that the latter properties are indeed fulfilled, observe that $\Psi\left(\kappa, B_{t}\right)>0$ for $\kappa>0$. This follows from the definition of $\Psi$, Lemma 1 , and $s\left(R_{t+1}, v\right) \in(0,1)$. Let me simplify the notation for the remainder of this proof and write $s(R(\kappa))$ for $s\left(R\left(\kappa, B_{t}\right), v\right)$. Then, one readily verifies that $\Psi_{\kappa}\left(\kappa, B_{t}\right)>0$ for $\kappa>0$ is assured if

$$
\left(s_{R}(R(\kappa)) \frac{R(\kappa)}{s(R(\kappa))}\right)\left(R_{\kappa}(\kappa) \frac{\kappa}{R(\kappa)}\right)<1+\varepsilon_{\kappa}^{A}\left(\kappa, \eta^{A}\right)+\varepsilon_{\kappa}^{B}(\kappa) .
$$

Observe with (3.3) and (3.14) that the left-hand side of (8.5) is $\varepsilon_{R}^{S}(\kappa) \cdot \varepsilon_{\kappa}^{R}(\kappa)$. From (4.5), the righthand side is equal to $1 / \varepsilon^{\kappa}$. Hence, (8.5) coincides with (4.11).

Next, I show that $\lim _{\kappa \rightarrow 0} \Psi\left(\kappa, B_{t}\right)=0$ and $\lim _{\kappa \rightarrow \infty} \Psi\left(\kappa, B_{t}\right)=\infty$. To make the argument, one has to consider both factors on the right-hand side of (8.3).

First, since $g^{A}\left(\kappa, \eta^{A}\right)$ is increasing in $\kappa$ on $\mathbb{R}_{++}$and bounded from below by zero, $\lim _{\kappa \rightarrow 0} g^{A}\left(\kappa, \eta^{A}\right)$ is finite and $\lim _{\kappa \rightarrow \infty} g^{A}\left(\kappa, \eta^{A}\right)$ is finite or infinite. Since $g^{B}(\kappa)$ is decreasing on $\mathbb{R}_{++}$and bounded from below by zero, $\lim _{\kappa \rightarrow 0} g^{B}(\kappa)$ is either finite or infinite and $\lim _{\kappa \rightarrow \infty} g^{B}(\kappa)$ is finite. As a consequence, $\lim _{\kappa \rightarrow 0}\left(1+\left(1+\eta^{A}\right) g^{A}\left(\kappa, \eta^{A}\right)\right) /\left(1+g^{B}(\kappa)\right)$ is finite, and $\lim _{\kappa \rightarrow \infty}\left(1+\left(1+\eta^{A}\right) g^{A}\left(\kappa, \eta^{A}\right)\right) /\left(1+g^{B}(\kappa)\right)$ is either finite or infinite.

Second, I have to know the $\operatorname{limits}_{\lim _{\kappa \rightarrow 0}} \kappa / s(R(\kappa))$ and $\lim _{\kappa \rightarrow \infty} \kappa / s(R(\kappa))$. As to the limit $\kappa \rightarrow 0$, the following cases must be considered. First, if $\lim _{\kappa \rightarrow 0} R(\kappa)=R(0)$ is finite, then $s(R(0)) \in(0,1)$ and $\lim _{\kappa \rightarrow 0} \kappa / s(R(\kappa))=0$. Second, if $\lim _{\kappa \rightarrow 0} R(\kappa)=R(0)$ is infinite, then $\lim _{\kappa \rightarrow \infty} s(R(\kappa))=$ $s(R(0)) \geq 0$. If $s(R(0))>0$, then it is immediate that $\lim _{\kappa \rightarrow 0} \kappa / s(R(\kappa))=0$. If $s(R(0))=0$, then savings goes to zero as the rental rate of capital approaches infinity. However, even in this case it holds that $\lim _{\kappa \rightarrow 0} \kappa / s(R(\kappa))=0$. To see this, consider the Euler equation of cohort $t$, $u^{\prime}\left(c_{t+1}^{o}\right)=u^{\prime}\left(c_{t}^{y}\right) / R(\kappa)$. By assumption, $\lim _{\kappa \rightarrow 0} R(\kappa)=\infty$ and $\lim _{\kappa \rightarrow 0} s(R(\kappa))=0$. Therefore,

$$
\lim _{\kappa \rightarrow 0} u^{\prime}\left(c_{t+1}^{o}\right)=\lim _{\kappa \rightarrow 0} \frac{u^{\prime}\left(c_{t}^{y}\right)}{R(\kappa)}=\lim _{\kappa \rightarrow 0} \frac{u^{\prime}\left((1-s(R(\kappa))) w_{t}\right)}{R(\kappa)}=\frac{u^{\prime}\left(w_{t}\right)}{\lim _{\kappa \rightarrow 0} R(\kappa)}=0 .
$$


Since $u$ satisfies the Inada condition, I find with the budget constraint of an old individual at $t+1$ the implication that

$$
\lim _{\kappa \rightarrow 0} c_{t+1}^{o}=\frac{w_{t}}{v} \lim _{\kappa \rightarrow 0}[R(\kappa) s(R(\kappa))]=\infty
$$

Next, observe that $f(\kappa)>\kappa f^{\prime}(\kappa)>0$ since $F_{2}>0$ for $\kappa>0$. Then, using (3.12) and $q^{B}=g^{B}(\kappa)$, I may express $\kappa R(\kappa)$ as

$$
\begin{aligned}
\kappa R(\kappa) & =B_{t}(1-\delta)\left(1+g^{B}(\kappa)\right)\left[\kappa f^{\prime}(\kappa)-\kappa i\left(g^{B}(\kappa)\right)\right] \\
& <B_{t}(1-\delta)\left(1+g^{B}(\kappa)\right)\left[f(\kappa)-\kappa i\left(g^{B}(\kappa)\right)\right] \equiv \hat{R}(\kappa) .
\end{aligned}
$$

Then, for $\kappa<1, \kappa R(\kappa)<\hat{R}(1)$. Therefore,

$$
\frac{s(R(\kappa))}{\kappa}=\frac{R(\kappa) s(R(\kappa))}{\kappa R(\kappa)}>\frac{R(\kappa) s(R(\kappa))}{\hat{R}(1)} .
$$

In light of (8.6), $\lim _{\kappa \rightarrow 0} s(R(\kappa)) / \kappa=\infty$, and $\lim _{\kappa \rightarrow 0} \kappa / s(R(\kappa))=0$ as desired. Therefore, $\lim _{\kappa \rightarrow 0} \Psi\left(\kappa, B_{t}\right)=0$.

Finally, note that $\lim _{\kappa \rightarrow \infty} \kappa / s(R(\kappa))=\infty$ since $\lim _{\kappa \rightarrow \infty} s(R(\kappa)) \in[0,1]$. Hence, $\lim _{\kappa \rightarrow \infty} \Psi\left(\kappa, B_{t}\right)=$ $\infty$.

To sum up, the right-hand side of (8.4) is increasing on $\mathbb{R}_{++}$approaching zero as $\kappa \rightarrow 0$ and infinity as $\kappa \rightarrow \infty$. Accordingly, there is a unique $\kappa$ that satisfies (4.9) given $\left(\kappa_{t}, B_{t}\right) \in \mathbb{R}_{++}^{2}$. With this value at hand, (4.10) delivers a unique $B_{t+1}>0$.

\subsection{Proof of Proposition 2}

This proposition follows immediately from (5.3), (5.4), Lemma 1, and Lemma 2.

\subsection{Proof of Lemma 3}

Consider (5.5). With $a_{t}$ and $b_{t}$ from (3.16) and (3.9) I find,

$$
\begin{aligned}
\frac{\partial V_{t}}{\partial q_{t}^{A}} & =A_{t-1}(1-\delta)\left(1+\eta^{A}\right) L_{t}\left[F_{2}\left(b_{t} K_{t}, a_{t} L_{t}\right)-i\left(q_{t}^{A}\right)-\left(1+\left(1+\eta^{A}\right) q_{t}^{A}\right) i^{\prime}\left(q_{t}^{A}\right)\right] \\
& +\eta^{A} A_{t-1}(1-\delta) L_{t}\left(1+\left(1+\eta^{A}\right) q_{t}^{A}\right) i^{\prime}\left(q_{t}^{A}\right)=\frac{\eta^{A} w_{t} L_{t}}{1+\left(1+\eta^{A}\right) q_{t}^{A}}>0 \\
\frac{\partial V_{t}}{\partial q_{t}^{B}} & =B_{t-1}(1-\delta) K_{t}\left[F_{1}\left(b_{t} K_{t}, a_{t} L_{t}\right)-i\left(q_{t}^{B}\right)-\left(1+q_{t}^{B}\right) i^{\prime}\left(q_{t}^{B}\right)\right]=0
\end{aligned}
$$

In equilibrium the expressions in brackets vanish in accordance with (8.1). Hence, (5.7) is shown. The results stated in (5.8) are immediate from Lemma 1, Lemma 2, and (5.6). 


\subsection{Proof of Proposition 3}

Recall that $V_{t+1}=V\left(b_{t+1} K_{t+1}, a_{t+1} L_{t+1}\right)$ denotes the equilibrium income under $(\lambda, v)$. With Lemma 1, Lemma 2, and (3.16) it is understood that

$$
q_{t+1}^{A}=g^{A}\left(\kappa\left(\frac{B_{t} K_{t+1}}{A_{t} L_{t+1}}\right), \eta^{A}\right) \quad \text { and } \quad q_{t+1}^{B}=g^{B}\left(\kappa\left(\frac{B_{t} K_{t+1}}{A_{t} L_{t+1}}\right)\right)
$$

Similarly, under $\left(\lambda^{\prime}, v^{\prime}\right)$ the equilibrium income is $V_{t+1}^{\prime}=V\left(b_{t+1}^{\prime} K_{t+1}^{\prime}, a_{t+1}^{\prime} L_{t+1}^{\prime}\right)$, where $q_{t+1}^{A \prime}$ and $q_{t+1}^{B \prime}$ differ from (8.10) as they now depend on $K_{t+1}^{\prime} / L_{t+1}^{\prime}$.

Claim 1 Consider $\lambda^{\prime}<\lambda$ sufficiently close. The proof involves two steps.

Step 1: For $\left(K_{t+1}, L_{t+1}\right)$ and $\left(K_{t+1}^{\prime}, L_{t+1}^{\prime}\right)$ sufficiently close, the first-order Taylor approximation of $V_{t+1}^{\prime}$ at $V_{t+1}$ is

$$
V_{t+1}^{\prime} \approx V_{t+1}+\frac{d V_{t+1}}{d K_{t+1}}\left(K_{t+1}^{\prime}-K_{t+1}\right)+\frac{d V_{t+1}}{d L_{t+1}}\left(L_{t+1}^{\prime}-L_{t+1}\right) .
$$

Here, $d V_{t+1} / d K_{t+1}$ and $d V_{t+1} / d L_{t+1}$ denote the total effect of changing $K_{t+1}$ or $L_{t+1}$ on $V_{t+1}$, respectively. As stated in (5.13) and (5.14) they comprise a direct effect equal to the respective factor price and the induced effect of (5.6). As explained in the main text, $d V_{t+1} / d K_{t+1}>0$ and $d V_{t+1} / d L_{t+1}>0$.

Step 2: To quantify the difference $K_{t+1}^{\prime}-K_{t+1}$, consider the first-order Taylor approximation

$$
K_{t+1}^{\prime} \approx K_{t+1}+\frac{\partial K_{t+1}}{\partial \lambda}\left(\lambda^{\prime}-\lambda\right),
$$

at $\lambda$. The derivative involved is obtained from

$$
s\left(R\left(\kappa\left(\frac{B_{t} K_{t+1}}{A_{t} L_{t}(1+\lambda)}\right), B_{t}\right), v\right) w_{t} L_{t}=K_{t+1},
$$

which restates (4.8) using Lemma 1, Lemma 2, and $L_{t+1}=L_{t}(1+\lambda)$ to uncover the dependency of $K_{t+1}$ on $\lambda$. Implicit differentiation delivers

$$
\frac{\partial K_{t+1}}{\partial \lambda}=\frac{K_{t+1}}{1+\lambda} \frac{-\varepsilon}{1-\varepsilon} \gtreqless 0,
$$

where $\varepsilon$ is evaluated at $\kappa_{t+1}$. Hence,

$$
K_{t+1}^{\prime} \gtreqless K_{t+1} \quad \Leftrightarrow \quad \varepsilon \gtreqless 0 .
$$

Finally, noting that $L_{t+1}^{\prime}-L_{t+1}=L_{t}\left(\lambda^{\prime}-\lambda\right)$ I have

$$
d V_{t+1} \equiv V_{t+1}^{\prime}-V_{t+1} \approx \frac{d V_{t+1}}{d K_{t+1}} \frac{\partial K_{t+1}}{\partial \lambda}\left(\lambda^{\prime}-\lambda\right)+\frac{d V_{t+1}}{d L_{t+1}} L_{t}\left(\lambda^{\prime}-\lambda\right),
$$

and straightforward manipulations deliver (5.9).

To prove (5.10) consider $d v_{t+1} \equiv v_{t+1}^{\prime}-v_{t+1}$, where $v_{t+1}=V_{t+1} /\left(L_{t}(v+1+\lambda)\right)$ and $v_{t+1}^{\prime}=$ $V_{t+1}^{\prime} /\left(L_{t}\left(v+1+\lambda^{\prime}\right)\right)$. With $d V_{t+1}$ of $(8.12)$ I have

$$
d v_{t+1} \approx \frac{d V_{t+1}}{L_{t}(v+1+\lambda)}-\frac{V_{t+1}\left(\lambda^{\prime}-\lambda\right)}{L_{t}(v+1+\lambda)^{2}}
$$


Hence,

$$
d v_{t+1} \lesseqgtr 0 \quad \Leftrightarrow \quad d V_{t+1}-v_{t+1} L_{t}\left(\lambda^{\prime}-\lambda\right) \lesseqgtr 0 .
$$

Straightforward manipulations using the results derived above reveal that (8.13) coincides with (5.10). Hence, Claim 1 of Proposition 3 is proven.

Claim 2 Consider $v^{\prime}>v$ sufficiently close. Again, the prove involves two steps.

Step 1: Taking into account that $L_{t+1}^{\prime}=L_{t+1}$, the first-order Taylor approximation at $\left(K_{t+1}, L_{t+1}\right)$ corresponding to (8.11) is now

$$
V_{t+1}^{\prime} \approx V_{t+1}+\frac{d V_{t+1}}{d K_{t+1}}\left(K_{t+1}^{\prime}-K_{t+1}\right) .
$$

Step 2: To quantify the difference $K_{t+1}^{\prime}-K_{t+1}$, consider the first-order Taylor approximation

$$
K_{t+1}^{\prime} \approx K_{t+1}+\frac{\partial K_{t+1}}{\partial v}\left(v^{\prime}-v\right)
$$

at $v$. The derivative involved may be directly obtained from (5.4) noting that $L_{t+1} \partial\left(K_{t+1} / L_{t+1}\right) / \partial v=$ $\partial K_{t+1} / \partial v$. Hence,

$$
\frac{\partial K_{t+1}}{\partial v}=\frac{s_{v}\left(R_{t+1}, v\right) w_{t} L_{t}}{1-\varepsilon}>0,
$$

where $\varepsilon$ is evaluated at $\kappa_{t+1}$. The sign follows from $s_{v}>0$ in conjunction with (4.11) requiring $\varepsilon<1$. Hence,

$$
K_{t+1}^{\prime} \gtreqless K_{t+1} \quad \Leftrightarrow \quad v^{\prime} \gtreqless v .
$$

With these results,

$$
d V_{t+1} \equiv V_{t+1}^{\prime}-V_{t+1} \approx \frac{d V_{t+1}}{d K_{t+1}} \frac{\partial K_{t+1}}{\partial v}\left(v^{\prime}-v\right)
$$

delivers (5.11).

To prove (5.12) consider again $d v_{t+1} \equiv v_{t+1}^{\prime}-v_{t+1}$. The result follows from the same steps that led to (8.13) with $v^{\prime}-v$ replacing $\lambda^{\prime}-\lambda$. Then, straightforward manipulations using the results derived above deliver inequality (5.12). This completes the proof of Proposition 3.

\subsection{Proof of Proposition 4}

1. " $\Rightarrow$ ": If condition (5.17) holds, then, at $q_{t}^{B}=\delta /(1-\delta)$, (3.10) and (3.12) deliver a unique $\kappa^{*} \in(0, \infty)$ since $f^{\prime \prime}(\kappa)<0$ on $\mathbb{R}_{++}$. To see that there also exists a unique $B^{*} \in \mathbb{R}_{++}^{2}$, rewrite (5.15) as $B^{*} s\left(R\left(\kappa^{*}, B^{*}\right), v\right)=$ const. $>0$. Since $s_{R}(\cdot) \geq 0$, the left-hand side is strictly increasing in $B^{*}$ taking on values form zero to infinity as $B^{*}$ varies on this interval. Hence, there is a unique value $B^{*}>0$ that satisfies (5.15).

" $\Leftarrow ":$ If $i^{\prime}(\delta /(1-\delta)) /(1-\delta)+i(\delta /(1-\delta)) \geq \lim _{\kappa \rightarrow 0} f^{\prime}(\kappa)$, then (3.12) delivers $m_{t}=0$, hence $\kappa_{t}=0$. If $\lim _{\kappa \rightarrow \infty} f^{\prime}(\kappa) \geq i^{\prime}(\delta /(1-\delta)) /(1-\delta)+i(\delta /(1-\delta))$ then (3.12) delivers $m_{t}=\infty$, hence $\kappa_{t}=\infty$. 
2. Since (5.16) determines $\kappa^{*}$, I obtain $g^{*}$ from Lemma 1 and (3.16). The stated findings about the steady-state growth factors of $a_{t}, w_{t}, c_{t}^{y}, c_{t}^{o}$, and $s_{t}$ are immediate from $a_{t}=A_{t}$, (8.2), (3.3), and the budget constraints. Steady-state growth of $K_{t}$ follows from (4.8). In steady state income of (5.5) can be expressed as

$$
V_{t}=a_{t} L_{t}\left[f\left(\kappa^{*}\right)-i\left(g\left(\kappa^{*}, \eta^{A}\right)\right)-\kappa^{*} i\left(\frac{\delta}{1-\delta}\right)\right] .
$$

Hence, the growth factor of $V_{t}$ is $\left(1+g^{*}\right)(1+\lambda)$ and the growth factor of $v_{t}$ is $\left(1+g^{*}\right)$. All other growth factors under $b$ ) result from (3.4) in conjunction with (E4) and (4.3). Finally, (3.16) gives $b_{t}=B^{*}$, and (8.2) delivers $R^{*}=B^{*} i^{\prime}(\delta /(1-\delta)) /(1-\delta)$.

\section{3. (a) Local Stability}

From the proof of Proposition 1, I know that (4.11) implies $\Psi_{\mathcal{K}}\left(\kappa_{t+1}, B_{t}\right)>0$. Similarly, one readily verifies that $\Psi_{B}\left(\kappa_{t+1}, B_{t}\right) \leq 0$ if $s_{R}(\cdot) \geq 0$. It is then straightforward to see that (4.9) defines a continuously differentiable function $\phi^{\kappa}: \mathbb{R}_{++}^{2} \rightarrow \mathbb{R}_{++}$, i. e., $\kappa_{t+1}=\phi^{\kappa}\left(\kappa_{t}, B_{t}\right)$. Consider (4.10) for $t+1$ and substitute $\kappa_{t+1}=\phi^{\kappa}\left(\kappa_{t}, B_{t}\right)$. This gives

$$
\begin{aligned}
B_{t+1} & =B_{t}(1-\delta)\left(1+g^{B}\left(\kappa_{t+1}\right)\right) \\
& =B_{t}(1-\delta)\left(1+g^{B}\left(\phi^{\kappa}\left(\kappa_{t}, B_{t}\right)\right)\right) \equiv \phi^{B}\left(\kappa_{t}, B_{t}\right),
\end{aligned}
$$

which is also a continuously differentiable function $\phi^{B}: \mathbb{R}_{++}^{2} \rightarrow \mathbb{R}_{++}$. Hence, with $\left(\kappa_{1}, B_{1}\right)$ given by $(4.10)$ and $(4.12)$, the dynamical system can be stated as

$$
\left(\kappa_{t+1}, B_{t+1}\right)=\phi\left(\kappa_{t}, B_{t}\right) \equiv\left(\phi^{\kappa}\left(\kappa_{t}, B_{t}\right), \phi^{B}\left(\kappa_{t}, B_{t}\right)\right), t=1,2, \ldots, \infty .
$$

The steady state is a fixed point of (8.16). To study the local behavior of the system around the steady state, I need the eigenvalues of the Jacobian $D \phi\left(\kappa^{*}, B^{*}\right)$. I study each of its four elements in turn.

i. First, consider $\phi^{\kappa}\left(\kappa_{t}, B_{t}\right)$. Implicit differentiation of (8.4) and evaluation at the steady state gives

$$
\phi_{\kappa}^{\kappa}\left(\kappa^{*}, B^{*}\right)=\frac{B^{*} \tilde{w}_{\kappa}\left(\kappa^{*}\right)}{\Psi_{\kappa}\left(\kappa^{*}, B^{*}\right)}>0,
$$

where use is made of $(8.2)$ and $\Psi_{\kappa}\left(\kappa^{*}, B^{*}\right)>0$. Assuming that the set $\Delta \kappa_{t}=0$ is stable in the vicinity of the steady state is then equivalent to the assumption that $\phi_{\mathcal{K}}^{\kappa}\left(\kappa^{*}, B^{*}\right) \in(0,1)$. Similarly, I obtain

$$
\phi_{B}^{\kappa}\left(\kappa^{*}, B^{*}\right)=\frac{\Psi\left(\kappa^{*}, B^{*}\right)-B^{*} \Psi_{B}\left(\kappa^{*}, B^{*}\right)}{B^{*} \Psi_{\kappa}\left(\kappa^{*}, B^{*}\right)}>0,
$$

since $\Psi_{B}\left(\kappa^{*}, B^{*}\right) \leq 0$.

ii. Second, consider $\phi^{B}\left(\kappa_{t}, B_{t}\right)$. From (8.15) I obtain

$$
\phi_{\mathcal{\kappa}}^{B}\left(\kappa^{*}, B^{*}\right)=B^{*}(1-\delta) g_{\mathcal{K}}^{B}\left(\kappa^{*}\right) \phi_{\kappa}^{\kappa}\left(\kappa^{*}, B^{*}\right)<0
$$

and

$$
\phi_{B}^{B}\left(\kappa^{*}, B^{*}\right)=1+B^{*}(1-\delta) g_{\kappa}^{B}\left(\kappa^{*}\right) \phi_{B}^{\kappa}\left(\kappa^{*}, B^{*}\right)<1 .
$$

Using (8.18) and the definition of $\Psi$ given in (8.3), I find $\phi_{B}^{B}\left(\kappa^{*}, B^{*}\right) \in(0,1)$ if $\varepsilon_{\mathcal{K}}^{S}\left(\kappa^{*}\right)<1+\varepsilon_{\kappa}^{A}\left(\kappa^{*}\right)$. The latter holds since $\varepsilon_{\kappa}\left(\kappa^{*}\right) \leq 0$. Hence, the set $\Delta B_{t}=0$ is stable in the vicinity of the steady state with monotonic convergence. 
Using (8.17) - (8.20), the required Jacobian may be written as

$$
D \phi\left(\kappa^{*}, B^{*}\right)=\left(\begin{array}{cc}
\phi_{\mathcal{K}}^{\kappa}\left(\mathcal{\kappa}^{*}, B^{*}\right) & \phi_{B}^{\kappa}\left(\kappa^{*}, B^{*}\right) \\
B^{*} g_{\kappa}^{B}\left(\kappa^{*}\right) \phi_{\mathcal{K}}^{\kappa}\left(\kappa^{*}, B^{*}\right) & 1+B^{*} g_{\mathcal{K}}^{B}\left(\kappa^{*}\right) \phi_{B}^{\kappa}\left(\mathcal{\kappa}^{*}, B^{*}\right)
\end{array}\right) .
$$

Its eigenvalues, $\mu_{1}, \mu_{2}$, are given by

$$
\mu_{1,2}=\frac{\phi_{\kappa}^{\kappa}+\phi_{B}^{B}}{2} \pm \sqrt{\left(\frac{\phi_{\kappa}^{\kappa}+\phi_{B}^{B}}{2}\right)^{2}-\phi_{\kappa}^{\kappa}}
$$

Both eigenvalues are real if $\left(\phi_{\kappa}^{\kappa}+\phi_{B}^{B}\right)^{2} \geq 4 \phi_{\kappa}^{\kappa}$. Since $2>\phi_{\kappa}^{\kappa}+\phi_{B}^{B}>0$, I have $1>$ $\mu_{1} \geq \mu_{2}>0$. Hence, the steady state is either a stable node if the weak inequality is strict or a focus if not. If $\left(\phi_{\kappa}^{\kappa}+\phi_{B}^{B}\right)^{2}<4 \phi_{\kappa}^{\kappa}$, then $D \phi$ has two distinct complex eigenvalues, and the steady state is a spiral sink since $\operatorname{det}(D \phi)=\phi_{\kappa}^{\kappa}<1$ (see, e.g., Galor (2007), Proposition 3.8). The stability of the sets $\Delta \kappa_{t}=0$ and $\Delta B_{t}=0$ imply a clockwise orientation of the spiral sink.

(b) Phase Diagram

First, consider the set $\Delta \kappa_{t}=0$. By definition, it includes all pairs $\left(B_{t}, \kappa_{t}\right) \in \mathbb{R}_{++}^{2}$ for which $\phi^{\kappa}\left(B_{t}, \kappa_{t}\right)-\kappa_{t}=0$. Implicit differentiation delivers

$$
\left.\frac{d B_{t}}{d \kappa_{t}}\right|_{\Delta \kappa_{t}=0}=\frac{1-\phi_{\kappa}^{\kappa}\left(B_{t}, \kappa_{t}\right)}{\phi_{B}^{\kappa}\left(B_{t}, \kappa_{t}\right)}>0 .
$$

The sign follows since the assumption that the $\Delta \kappa_{t}=0$ - locus is stable is equivalent to $\phi_{\kappa}^{\kappa}\left(B_{t}, \kappa_{t}\right) \in(0,1)$. Moreover, $\phi_{B}^{\kappa}\left(B_{t}, \kappa_{t}\right)>0$, i. e., the sign of (8.18) is preserved outside the steady state.

Second, consider the set $\Delta B_{t}=0$. By definition, it includes all pairs $\left(B_{t}, \kappa_{t}\right) \in \mathbb{R}_{++}^{2}$ for which $\phi^{B}\left(B_{t}, \kappa_{t}\right)-B_{t}=0$. Implicit differentiation delivers

$$
\left.\frac{d B_{t}}{d \kappa_{t}}\right|_{\Delta B_{t}=0}=\frac{\phi_{\kappa}^{B}\left(B_{t}, \kappa_{t}\right)}{1-\phi_{B}^{B}\left(B_{t}, \kappa_{t}\right)}=-\frac{\phi_{\kappa}^{\kappa}\left(B_{t}, \kappa_{t}\right)}{\phi_{B}^{\kappa}\left(B_{t}, \kappa_{t}\right)}<0
$$

\subsection{Proof of Proposition 5}

The steady-state efficient capital intensity is given by (5.16). Since $g^{B}(\kappa)$ is independent of $\lambda$ and $v$, I have $\kappa^{*}=\kappa^{* \prime}$. Moreover, since $s_{v}\left(R\left(\kappa^{*}, B^{*}\right), v\right)>0, s_{R}\left(R\left(\kappa^{*}, B^{*}\right), v\right) \geq 0$, and $R_{B}\left(\kappa^{*}, B^{*}\right)>0$, (5.15) also delivers $\lambda>\lambda^{\prime} \Rightarrow B^{*}>B^{* \prime}$ and $v^{\prime}>v \Rightarrow B^{* \prime}<B^{*}$.

\subsection{Proof of Proposition 6}

I start with a result characterizing the convergence of the two economies before I turn to Claim 1 and 2 of Proposition 6. 
Result 1 The sequences $\left\{\kappa_{t}^{\prime}\right\}_{t=1}^{\infty}$ and $\left\{\kappa_{t}\right\}_{t=1}^{\infty}$ are such that

$$
\begin{aligned}
\kappa_{1}^{\prime} & =\kappa_{1}, \\
\kappa_{t}^{\prime} & >\kappa_{t} \text { for all } t=2,3, \ldots, \tau, \text { where } \tau<\infty, \\
\lim _{t \rightarrow \infty} \kappa_{t}^{\prime} & =\lim _{t \rightarrow \infty} \kappa_{t}=\kappa^{*} .
\end{aligned}
$$

Proof of Result 1 The proof is by induction.

First, consider the periods $t=1$ and $t=2$, the base case. For period $t=1$ the initial conditions of both economies are the same. Then, according to (4.6) of Lemma 2 it holds that $\kappa_{1}^{\prime}=\kappa_{1}$.

In period $t=2$, the older economy has a greater capital-labor ratio, i.e., $\left(K_{2} / L_{2}\right)^{\prime}>\left(K_{2} / L_{2}\right)$. This follows from (5.3) and (5.4) and, thus, is independent of the source of aging. Invoking (4.7) delivers $\kappa_{2}^{\prime}>\kappa_{2}$.

Next, consider the induction step for some period $\infty>\tau>2$. Suppose that the sequences $\left\{\mathcal{K}_{t}^{\prime}\right\}_{t=2}^{t=\tau}$ and $\left\{\kappa_{t}\right\}_{t=2}^{t=\tau}$ are such that $\kappa_{t}^{\prime}>\kappa_{t}$. Then, it follows that

$$
B_{\tau}^{\prime}=B_{1}(1-\delta)^{\tau-1} \prod_{t=2}^{\tau}\left(1+g^{B}\left(\kappa_{t}^{\prime}\right)\right)<B_{\tau}=B_{1}(1-\delta)^{\tau-1} \prod_{t=2}^{\tau}\left(1+g^{B}\left(\kappa_{t}\right)\right),
$$

and, for all $\tau$,

$$
\frac{B_{\tau}}{B_{\tau}^{\prime}}<\left(\frac{s\left(v^{\prime}\right)}{s(v)}\right)\left(\frac{1+\lambda}{1+\lambda^{\prime}}\right)=\lim _{\tau \rightarrow \infty}\left(\frac{B_{\tau}}{B_{\tau}^{\prime}}\right)=\frac{B_{\tau}^{*}}{B_{\tau}^{* \prime}} .
$$

For the periods $\tau$ and $\tau+1$, the evolution of $\kappa_{t}$ is determined by (4.9). Under the assumptions of Proposition 6 , the latter equation may be written as

$$
B_{t} \frac{s(v)}{1+\lambda} \tilde{w}\left(\kappa_{t}\right)=\kappa_{t+1} \frac{1+\left(1+\eta^{A}\right) g^{A}\left(\kappa_{t+1}, \eta^{A}\right)}{1+g^{B}\left(\kappa_{t+1}\right)} .
$$

The right-hand side of (8.24) is strictly increasing in $\kappa_{t+1}$. The left-hand side is strictly increasing in $\kappa_{t}$. Moreover, in light of (8.23), it holds at $t=\tau$ that

$$
B_{\tau}^{\prime} \frac{s\left(v^{\prime}\right)}{1+\lambda^{\prime}}>B_{\tau} \frac{s(v)}{1+\lambda} .
$$

Therefore, $\kappa_{\tau+1}^{\prime}>\kappa_{\tau+1}$ for all $\kappa_{\tau}^{\prime} \geq \kappa_{\tau}$.

Finally, from Proposition $4, \lim _{t \rightarrow \infty} \kappa_{t}^{\prime}=\lim _{t \rightarrow \infty} \kappa_{t}=\kappa^{*}$.

Next, consider steady-state net output of (8.14). It follows that

$$
\lim _{t \rightarrow \infty} \frac{V_{t}^{\prime}}{V_{t}}=\lim _{t \rightarrow \infty} \frac{A_{t}^{\prime} L_{t}^{\prime}}{A_{t} L_{t}}
$$

Result 1 in conjunction with Lemma 1 and (3.16) implies that $\lim _{t \rightarrow \infty} A_{t}^{\prime} / A_{t}>1$. This proves Claim 1 of Proposition 6 since $L_{t}^{\prime}=L_{t}$. Dividing net output of (8.14) by the (young) labor force reveals that

$$
\lim _{t \rightarrow \infty} \frac{V_{t}^{\prime} / L_{t}^{\prime}}{V_{t} / L_{t}}=\lim _{t \rightarrow \infty} \frac{A_{t}^{\prime}}{A_{t}}>1
$$

Using (8.2) delivers the same finding for $\lim _{t \rightarrow \infty}\left(w_{t}^{\prime} / w_{t}\right)$. This completes the proof of Proposition 6. 


\section{References}

ACEMoglu, D. (2003): "Labor- and Capital-Augmenting Technical Change," Journal of European Economic Association, 1(1), 1-37.

(2009): Introduction to Modern Economic Growth. Princeton University Press, Princeton, New Jersey.

(2010): “When Does Labor Scarcity Encourage Innovation?," Journal of Political Economy, 118(6), 1037-1078.

Acemoglu, D., AND S. Johnson (2007): "Disease and Development: The Effect of Life Expectancy on Economic Growth," Journal of Political Economy, 115(6), 925-985.

Allais, M. (1947): Economie et Intérêt. Imprimerie National, Paris.

Ashraf, Q. H., A. Lester, AND D. N. Weil (2009): “When Does Improving Health Raise GDP?," in NBER Macroeconomics Annual 2008, Volume 23, NBER Chapters, pp. 157-204. National Bureau of Economic Research, Inc.

Blanchard, O. J. (1985): “Debt, Deficits, and Finite Horizons," Journal of Political Economy, 93, 223-247.

Bloom, D. E., D. Canning, And B. Graham (2003): "Longevity and Life-Cycle Savings," Scandinavian Journal of Economics, 105(3), 319-338.

Bommier, A., AND R. D. LeE (2003): “Overlapping Generations Models with Realistic Demography," Journal of Population Economics, 16(1), 135-160.

BÖRsCh-Supan, A. (2012): "Policy Mixes in the Current European Pension Reform Process," CESifo DICE Report 4/2012, pp. 9-15.

BÖs, D., AND R. K. vON WeIZsëCKeR (1989): “Economic Consequences of an Aging Population," European Economic Review, 33, 345-354.

BouceKKine, R., D. DE LA CROIX, AND O. LiCANDro (2002): “Vintage Human Capital, Demographic Trends, and Endogenous Growth," Journal of Economic Theory, 104, 340-375.

Cervellati, M., AND U. Sunde (2011): "Life Expectancy and Economic Growth: the Role of the Demographic Transition," Journal of Economic Growth, 16(2), 99-133.

(2013): “The Economic and Demographic Transition, Mortality, and Comparative Development," IZA, Discussion Paper No. 7199.

Chakraborty, S. (2004): "Endogenous Lifetime and Economic Growth," Journal of Economic Theory, 116, 119-137.

Cutler, D. M., A. Deaton, AND A. Lleras-Muney (2006): “The Determinants of Mortality," Journal of Economic Perspectives, 20(3), 97-102.

DE LA CRoix, D., AND O. LicANDRO (1999): “Life Expectancy and Endogenous Growth," Economics Letters, 65, 255-263. 
DE LA CRoix, D., AND P. Michel (2002): A Theory of Economic Growth - Dynamics and Policy in Overlapping Generations. Cambridge University Press, Cambridge, UK.

DiAmond, P. A. (1965): “National Debt in a Neoclassical Growth Model," American Economic Review, 55(5), 1126-1150.

DRANDAKIS, E. M., AND E. S. Phelps (1966): “A Model of Induced Invention, Growth, and Distribution," The Economic Journal, 76, 823-840.

European COMmission - ECONOMiC AND FinANCiAl AfFAirs - AMECO (2013): “Update May 2013," European Commission, http://ec.europa.eu/economy_finance/ameco/user/serie/SelectSerie.cfm (accessed on August 28, 2013).

FEYRER, J. (2007): “Demographics and Productivity," The Review of Economics and Statistics, 89(1), 100-109.

FRANKel, M. (1962): “The Production Function in Allocation and Growth: A Synthesis," American Economic Review, 52(5), 995-1022.

FutAGAmi, K., AND T. NAKAjima (2001): “Population Aging and Economic Growth," Journal of Macroeconomics, 23, 31-44.

GALOR, O. (2007): Discrete Dynamical Systems. Springer Verlag, Berlin - Heidelberg.

_ (2011): Unified Growth Theory. Princeton University Press, Princeton, NJ.

Groneck, M., A. Ludwig, AND A. Zimper (2011): “A Life-Cycle Consumption Model with Ambiguous Survival Beliefs," Netspar Discussion Papers 03/2011-044.

HazAN, M., AND H. ZoABI (2006): “Does Longevity Cause Growth? A Theoretical Critique," Journal of Economic Growth, 11(4), 363-376.

Heer, B., AND A. Irmen (2009): "Population, Pensions, and Endogenous Economic Growth," Center for Economic Policy Research (CEPR), London, Discussion Paper, No. 7172.

Hellwig, M., AND A. IRmen (2001): “Endogenous Technical Change in a Competitive Economy," Journal of Economic Theory, 101, 1-39.

HICKS, J. R. (1932): The Theory of Wages. Macmillan, London, 1st edn.

Irmen, A. (2012): "Endogenous Task-Based Technical Change - Factor Scarcity and Factor Prices," mimeo, CREA, Center for Research in Economic Analysis, University of Luxembourg.

(2013): "A Generalized Steady-State Growth Theorem," CREA Discussion Paper Series 2013-26, Center for Research in Economic Analysis, University of Luxembourg.

KALDOR, N. (1961): "Capital Accumulation and Economic Growth," in The Theory of Capital, ed. by F. A. Lutz, and D. C. Hague, pp. 177-222. Macmillan \& Co. LTD., New York: St. Martin's Press.

KIRK, D. (1996): “Demographic Transition Theory,” Population Studies, 50(3), 361-387. 
Klump, R., P. McAdam, AND A. Willman (2007): "Factor Substitution and Factor Augmenting Technical Progress in the US: A Normalized Supply-Side System Approach," Review of Economics and Statistics, 89(1), 183-192.

Kuehnel, J. (2011): “Population Aging, the Composition of Government Spending, and Economic Growth (in a Heterogeneous Infinitely-Lived Agent Framework)," mimeo, University of Heidelberg.

LI, H., J. ZHANG, AND J. ZHANG (2007): “Effects of Longevity and Dependency Rates on Saving and Growth: Evidence from a Panel of Cross Countries," Journal of Development Economics, (84), 138-154.

LORENTZEN, P., J. MCMillan, AND R. WACZIARG (2008): “Death and development,” Journal of Economic Growth, 13(2), 81-124.

LUCAS, R. E. (1988): “On the Mecanics of Economic Development," Journal of Monetary Economics, 22(5), 3-42.

MAdDison, A. (2001): The World Economy: A Millennial Perspective. Organisation for Economic Co-operation and Development (OECD), Paris.

Merkel, A. (2009): “Wachstum. Bildung. Zusammenhalt. Deutschland zu neuer Stärke führen government declaration of chancellor Merkel in the German Federal Parliament 2009," Presseund Informationsamt der Bundesregierung.

Michel, P., AND D. DE LA Croix (2000): "Myopic and Perfect Foresight in the OLG Model," Economics Letters, 67, 53-61.

NiePelt, D., AND M. GonZALEZ-Eiras (2012): “Ageing, Government Budgets, Retirement, and Growth," European Economic Review, 56, 97-115.

Nishimura, K. G., K. MinetaKi, M. ShiRAi, AND F. KuROKAWA (2002): “Effects of Information Technology and Aging Work Force on Labor Demand and Technological Progress in Japanese Industries: 1980-1998," CIRJE F-Series CIRJE-F-145, CIRJE, Faculty of Economics, University of Tokyo.

Oeppen, J., AND J. W. VAupel (2002): “Broken Limits to Life Expectancy," Science, 296(5570), 1029-1031.

PrettNer, K. (2013): "Population Aging and Endogenous Economic Growth," Journal of Population Economics, 26, 811-834.

Prskawetz, A., T. Kögel, W. Sanderson, And S. Scherbov (2007): “The Effects of Age Structure on Economic Growth: An Application of Probabilistic Forecasting to India," International Journal of Forecasting, 23(4), 587-602.

Romer, P. M. (1986): "Increasing Returns and Long-Run Growth," Journal of Political Economy, 94, 1002-1037.

(1990): “Endogenous Technological Change," Journal of Political Economy, 98(5), S71-S102.

SAmuelson, P. A. (1958): “An Exact Consumption-Loan Model of Interest with or without the Social Contrivance of Money," Journal of Political Economy, 66, 467-482. 
SoARes, R. R. (2005): "Mortality Reductions, Educational Attainment, and Fertility Choice," American Economic Review, 95(3), 580-601.

Solow, R. M. (1956): "A Contribution to the Theory of Economic Growth," Quarterly Journal of Economics, 70(1), 65-94.

SWAN, T. W. (1956): "Economic Growth and Capital Accumulation," Economic Record, 32, 334361.

Tirole, J. (1985): “Asset Bubbles and Overlapping Generations," Econometrica, 53(6), 1499-1528.

United Nations (2013): “World Population Prospects: The 2012 Revision, CD-ROM Edition," United Nations, Department of Economic and Social Affairs, Population Division, New York, http://esa.un.org/unpd/wpp/Excel-Data/population.htm (accessed on August 14, 2013).

UzAWA, H. (1961): "Neutral Inventions and the Stability of Growth Equilibrium," Review of Economic Studies, 28(2), 117-124.

WeIL, D. (2008): "Population Aging," in The New Palgrave Dictionary of Economics, ed. by S. N. Durlauf, and L. E. Blume. Palgrave Macmillan, New York, 2nd edn.

WORLD BANK (2013): "World Development Indicators," The World Bank, http://data.worldbank.org/indicator/SP.POP.DPND.OL (accessed on August 28, 2013).

World Health ORGANizATION (2009): “How can health systems respond to population ageing?," Policy Brief 10.

YAARI, M. (1965): "Uncertain Lifetime, Life Insurance and the Theory of the Consumer," Review of Economic Studies, 32(2), 137-150.

ZEIRA, J. (1998): “Workers, Machines, And Economic Growth," Quarterly Journal of Economics, 113(4), 1091-1117.

ZHANG, J., J. ZHANG, AND R. LeE (2001): "Mortality Decline and Long-Run Economic Growth," Journal of Public Economics, 80, 485-507. 